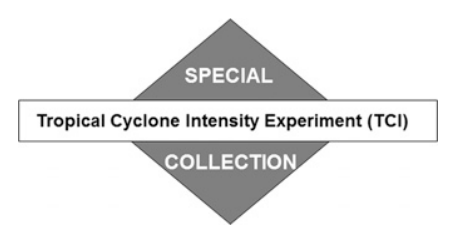

\title{
Adjoint-Derived Impact of Assimilated Observations on Tropical Cyclone Intensity Forecasts of Hurricane Joaquin (2015) and Hurricane Matthew (2016)
}

\author{
BRETT T. HOOVER AND CHRIS S. VELDEN \\ Space Science and Engineering Center, University of Wisconsin-Madison, Madison, Wisconsin
}

(Manuscript received 17 January 2020, in final form 11 June 2020)

\begin{abstract}
The adjoint-derived observation impact method is used as a diagnostic to derive the impact of assimilated observations on a metric representing the forecast intensity of a tropical cyclone (TC). Storm-centered composites of observation impact and the model background state are computed across 6-hourly analysis/forecast cycles to compute the composite observation impact throughout the life cycle of Hurricane Joaquin (2015) to evaluate the impact of in situ wind and temperature observations in the upper and lower troposphere, as well as the impact of brightness temperature and precipitable water observations, on intensity forecasts with forecast lengths from 12 to $48 \mathrm{~h}$. The compositing across analysis/forecast cycles allows for the exploration of consistent relationships between the synoptic-scale state of the initial conditions and the impact of observations that are interpreted as flow-dependent interactions between model background bias and correction by assimilated observations on the TC intensity forecast. The track of Hurricane Matthew (2016), with an extended period of time near the coasts of Florida, Georgia, and the Carolinas, allows for a comparison of the impact of aircraft reconnaissance observations with the impact of nearby overland rawinsonde observations available within the same radius of the TC.
\end{abstract}

\section{Introduction}

The evaluation of observing system changes on the forecast has been a crucial part of advancing operational numerical weather prediction (NWP), which has seen significant gains in forecast skill in the last few decades through advancement of data assimilation (Bauer et al. 2015). Often, this evaluation is obtained through observing system experiments (OSEs) in which observations are either excluded or added to assimilation, relative to a control, to assess their impact on forecast skill (e.g., Andersson et al. 1991; Bouttier and Kelly 2001; Zapotocny et al. 2007, 2008; Hilton et al. 2009; Lupu et al. 2012; Bauer et al. 2014). These experiments are capable of assessing this impact but at a very high computational cost. In addition, OSEs can provide an incomplete picture of the value of observations because the exclusion of routinely assimilated observations will necessarily redistribute weighting coefficients on the remaining observations, possibly allowing remaining observations to degrade the analysis if the assimilation system was optimally tuned to include the excluded observations (Gelaro and Zhu 2009).

Corresponding author: Brett T. Hoover, brett.hoover@ssec.wisc.edu
Alternatively, the impact of assimilated observations can be estimated through the sensitivity of the forecast error to the assimilated observations using the adjoint of the forecast model and the data assimilation system (Langland and Baker 2004). This allows for an estimate of each individual observation's contribution to the reduction in forecast error. Observation impact computed using the adjoint method has become a routine monitoring technique used at major centers including the Naval Research Laboratory (NRL; Langland and Baker 2004), the European Centre for Medium-Range Weather Forecasts (Cardinali 2009), the Met Office (Lorenc and Marriott 2014), the Japan Meteorological Agency (Ishibashi 2010), and the Korea Meteorological Administration (Kim and Kim 2014, 2018), as well as the NASA Global Modeling and Assimilation Office and Environment and Climate Change Canada (Gelaro et al. 2010). In operational usage, the impact of observations is computed for the $24-\mathrm{h}$ forecast on an energybased forecast error norm evaluated globally from the surface through the depth of the troposphere and lower stratosphere, relative to self-analysis. A strategy to estimate observation impact has been developed in ensemble systems as well (e.g., Liu and Kalnay 2008; Kalnay et al. 2012; Kunii et al. 2012; Ota et al. 2013), 
which does not require the use of an adjoint, but relies on the necessarily limited phase-space exploration provided by an ensemble and requires empirical localization strategies to remove the influence of spurious correlations at long distances.

The observation-impact technique has been applied to investigate the relative contributions of observations to reducing forecast error for a variety of applications. Observation impact has been used to assess the relative contribution of various satellite platforms (Joo et al. 2013; Cardinali and Healy 2014), and to provide detailed estimates of the value added in observing system experiments by special observation datasets like reconnaissance campaign dropsondes (Langland 2005), high-density satellite derived wind observations (Kim et al. 2017), experimental observational coverage strategies (Reale et al. 2018), model reconfiguration allowing for assimilation of more observations over a deeper layer of the stratosphere (Charron et al. 2012), and assimilation of commercially available observations (Zhang et al. 2015). It has also been applied in observing system experiments to provide detailed information on the impact of synthetic observations with implications for issues of analysis bias and redundancy of observation impact across different observation platforms (Hoover and Langland 2017). The observation-impact method provides complementary but not necessarily overlapping information with observing system experiments (Gelaro and Zhu 2009). Some diagnostic studies using observation impact focus on specific regions of the forecast, like subset regions covering the full track of tropical cyclones throughout a cycled experiment (Jung et al. 2013) or small regions centered on a single weather system (Holdaway et al. 2014). The technique has been expanded beyond NWP analysis/forecast systems to use in ocean models (Cummings and Smedstad 2014) and high-resolution two-dimensional surface analysis models (Tyndall and Horel 2013). A sensitivity measurement based on the ensemble Kalman Filter has been adapted to investigate the impact of carbon dioxide $\left(\mathrm{CO}_{2}\right)$ observations on the optimized $\mathrm{CO}_{2}$ flux in a $\mathrm{CO}_{2}$ inversion system $(\mathrm{Kim}$ et al. 2014).

This study expands the application of observation impact as a diagnostic tool by computing the impact of observations on a dynamical aspect of the forecast rather than computing the impact on forecast error. Through use of a norm representing the intensity of a tropical cyclone (TC), and storm-centered compositing of observation impact throughout the TC life cycle, a noise reduction for the observation impact on the forecast intensity of the TC is achieved and systemic impacts from various observation types are compared to features of the TC's near and remote environments. In this way, some of the flow-dependent relationships between features of the atmosphere and TC intensity are investigated from the perspective of the role of model background bias and its influence, or the erosion of its influence through data assimilation, on the intensity forecast. Repeated correction of model background errors by observations that yield consistent changes to the TC intensity forecast at forecast lengths from 12 to $48 \mathrm{~h}$ are revealed by composites, providing new insight into the impact of observations on TC forecast intensity. A description of the NWP model, data assimilation system, and observational data is provided in section 2 . In section 3 , the method for deriving the observation impact on the TC intensity forecast is described, as well as the method for computing storm-centered composites of the observation impact and displaying them in a grid space for comparison to the model background state. Results of the method applied to Hurricane Joaquin (2015) are provided in section 4, along with an examination of the relative impact of reconnaissance dropsondes in comparison with nearby routine rawinsonde observations for Hurricane Matthew (2016). Conclusions and directions for future work are presented in section 5.

\section{Model and data}

Experiments are performed in the Navy Global Environmental Model (NAVGEM). The description here is adapted from Hoover and Langland (2017), which used the same model and platform and further description is provided there. The NAVGEM is an upgrade of the Navy Operational Global Atmospheric Prediction System (NOGAPS; Hogan and Rosmond 1991) spectral model redesigned with a semi-Langrangian advection scheme, run at T425 spectral resolution with 60 vertical levels. The 6-hourly analysis cycle is performed using the NRL Atmospheric Variational Data Assimilation System-Accelerated Representer (NAVDAS-AR; Xu et al. 2005), which is a four-dimensional variational data assimilation system in observation space (Rosmond and $\mathrm{Xu}$ 2006) utilizing the tangent linear approximation of the NOGAPS model and its adjoint (Rosmond 1997). The analysis is cycled throughout the life cycle of each tropical cyclone, starting from archived spectral history files from the U.S. Navy Fleet Numerical Meteorology and Oceanography Center (FNMOC) operational analysis archive. Bias correction coefficients for assimilation of radiances are likewise obtained from FNMOC to allow for immediate cycling without the need for a spin-up period to establish the bias correction. Following initialization, the system performs a 6-h analysis-forecast cycle that produces atmospheric analyses at 0000, 0600, 1200, and 1800 UTC, with 54-h forecasts produced for each cycle. 
All (FNMOC) operationally assimilated observation types are assimilated: surface land/ship observations, aircraft observations, atmospheric motion vectors (AMVs) from geostationary satellite imagery and low-Earth-orbiting satellite imagery, ocean surface wind observations obtained from the Special Sensor Microwave Imager (SSM/I), ocean surface scatterometer winds, rawinsonde observations, synthetic tropical cyclone observations (Goerss and Jeffries 1994), total precipitable water measurements, brightness temperatures, ozone observations, and bending angle observations from global positioning satellite radio occultation.

\section{Method}

\section{a. Observation impact on forecast TC intensity}

This study builds from previous work by applying the observation-impact technique to a response function defining the forecast intensity of a tropical cyclone. In this way, rather than estimating the impact of each assimilated observation on a global, energy-based forecast error norm, the impact of assimilated observations is estimated for the forecast intensity of the TC. This is achieved by three changes to the method described in Langland and Baker (2004), and the reader is directed to their appendix for details on the derivation of observation impact.

First, the response function is redefined to describe the intensity of a TC in the forecast state. For each forecast, the central minimum pressure of a chosen TC is identified in the forecast state, and a response function $R$ is defined:

$$
R=\left.\sum_{i, j \in D} p_{s}\right|_{i, j}
$$

where $p_{s}$ represents the surface pressure for all grid points indexed zonally by $i$ and meridionally by $j$ in a box $D$ centered over the TC. Any impact on the forecast that raises surface pressures in the box $D$ increases $R$ and can be interpreted as a weakening of the TC. Conversely, any impact on the forecast that lowers surface pressures in the box $D$ decreases $R$ and can be interpreted as an intensification of the TC. Response functions of this form have been used in other studies investigating the adjoint-derived sensitivity of the forecast intensity of tropical storms (Hoover 2015) and midlatitude cyclones (Ancell and Mass 2006; Chu and Yi 2016) to the model initial state, while other studies have used response functions defined by summed three-dimensional volumes of kinetic energy (Doyle et al. 2012) or vorticity (Vukićević and Raeder 1995; Langland and Errico 1996) evaluated in a box centered on the cyclone extending from the surface into the lower-to-middle troposphere. The gradient of $R$ with respect to the model initial state $x_{0}$ is computed by initializing the adjoint of the forecast model with the gradient of $R$ with respect to the forecast state $x_{f}$ and evolving the gradient backward along the forecast trajectory to the initial state:

$$
\frac{\partial R}{\partial x_{0}}=L^{\mathrm{T}} \frac{\partial R}{\partial x_{f}},
$$

where $L^{\mathrm{T}}$ represents the adjoint model defined as the transpose of the tangent linear approximation of the nonlinear forecast model. The gradient of $R$ with respect to the observations $y$ is computed by evolving $\partial R / \partial x_{0}$ through the adjoint of the data assimilation system:

$$
\frac{\partial R}{\partial y}=D^{\mathrm{T}} \frac{\partial R}{\partial x_{0}},
$$

where $D^{\mathrm{T}}$ is the transpose of the NAVDAS-AR achieved by reordering of operations. Details on this calculation can be found in Langland and Baker (2004).

Since the TC intensity response function [Eq. (1)] is defined for a single model trajectory, the second change to the method of Langland and Baker (2004) is that sensitivity of $R$ to observations is evaluated along the background trajectory alone (i.e., the model trajectory initialized from the background state, prior to assimilation of observations for the current cycle). In this way, the forecast intensity of the TC along the background trajectory is assumed as a baseline, and the observation impact represents the modulation to the forecast TC intensity from the background trajectory as a result of assimilating observations at the initial time, blending the observational information with the model background state and allowing that perturbation to the model initial state to evolve through the forecast to impact $R$. In prior studies of observation impact, the response function has been defined as the difference between two quadratic error expressions, which requires the use of sensitivity gradients along both the background and analysis trajectories. Since Eq. (1) is a function of the model state, rather than the difference between two quadratic expressions, there is no necessity to compute sensitivities on both the background and analysis trajectories. See the appendix of Langland and Baker (2004) for details.

The third and final change to the method is to estimate the observation impact across a range of forecast lengths instead of only the 24-h forecast. In this study, the observation impact is computed for the TC intensity in the 12-, 24-, 36-, and 48-h forecast. Investigation of observation impact at various forecast lengths allows for an examination of how the distribution of high-impact 
observations-across observation type (i.e., observing platform), observed variable, and observed pressure level-varies as forecast length changes. For each forecast length the impact is computed as the inner product of $\partial R / \partial y$ and the innovation, defined as the difference between the observation and the model background state $x_{b}$ and a linear operator $H$ that projects the model state into observation space:

$$
\delta R=\left\langle\left(y-H x_{b}\right), \frac{\partial R}{\partial y}\right\rangle .
$$

While it would otherwise be valuable to investigate forecast lengths beyond $48 \mathrm{~h}$, the accuracy of the adjoint model relies on the appropriateness of the tangent linear approximation, and thus the adjoint model is quantitatively accurate for only a limited range of the forecast. Previous studies have demonstrated that the linear approximation is appropriate for $48-72-\mathrm{h}$ forecasts (Errico et al. 1993) where highly nonlinear moist convection does not dominate (Errico and Raeder 1999; Mahfouf 1999). Previous adjoint-based sensitivity studies of TC intensity have been restricted to 18-24-h forecasts (Doyle et al. 2012; Hoover 2015). Singular vector analysis using an adjoint model approach, which identifies the fastest growing perturbations in a forecast relative to a chosen initial/final metric, forecast length, and verification region (e.g., Palmer et al. 1998), have been employed to investigate tropical cyclones for forecast lengths of $36-48 \mathrm{~h}$ (Peng and Reynolds 2006; Chen et al. 2009; Kim and Jung 2009; Reynolds et al. 2009; Kim et al. 2011). Based on these previous studies, the 48 -h forecast is chosen as the limit to which observation impact can conceivably be computed and compared. Because sensitivity is computed on the background trajectory, the 6-54-h forecast initialized from the previous 6-hourly analysis is used to define this 48 -h forecast period.

\section{b. Storm-centered observation-space compositing}

For each assimilated observation, the observation impact on the 12-, 24-, 36-, and 48-h TC intensity is computed and normalized by the area of the response function box $D$, which is defined using an $11^{\circ} \times 11^{\circ}$ box for Hurricane Joaquin (2015), with the area of each response function box varying slightly by latitude. The zonal and meridional distance of the observation from the latitude and longitude of the TC center is computed. Observations within $4000 \mathrm{~km}$ of the TC center are retained for compositing onto a storm-centered grid with 163 points in the zonal and meridional directions and 34 pressure levels, creating three-dimensional grid boxes that are $50.31 \mathrm{~km}$ on a side and $30 \mathrm{hPa}$ deep in the vertical direction from 1040 to $100 \mathrm{hPa}$. Observation impact at each forecast lead time are averaged in each box for each observed variable, representing the composited per-observation impact for each observed variable in each grid box. Observation impact for Joaquin is composited across forecasts initialized from each 6-hourly analysis period from 0600 UTC 30 September to 1800 UTC 4 October 2015.

In addition, model-state variables are interpolated from the $1^{\circ} \times 1^{\circ}$ grid on pressure levels to the observation's three-dimensional location (latitude, longitude, pressure level) using bilinear interpolation in the horizontal and $\log$ interpolation in the vertical. These model-state quantities include vorticity, divergence, streamfunction, velocity potential, and dewpoint depression, obtained from the model background state $\left(x_{b}\right)$, providing information about the state of the initial conditions prior to assimilation of observations. These model-state variables are averaged in each grid box to produce a storm-centered composite of the model state in which observations are assimilated, which is used to compare observation impacts to features of the near- and far-storm environment in section 4.

Composite plots are computed by vertically averaging the observation impact through some chosen depth of the $30 \mathrm{hPa}$ pressure slabs, and a mean model state within each column is likewise computed as a vertical average within every horizontal gridbox location. Since columns only have a horizontal footprint of $50.31 \mathrm{~km}$ on a side, there are many cases where columns with data are adjacent to columns with missing values (no observations present in that box), especially away from the continental United States where in situ observations are sparse. Observation impact retains its missing-value columns, but columns with fewer than six observations are excluded from the analysis and set to a missing value, since these low-density regions can produce large outliers in impact. To compute a relatively smooth model state field, missing values for the model state are eliminated through smoothing. The field is recursively convolved with a $3 \times 3$ smoother molecule eight times, each time involving a two-stage process in which the field is convolved with missing values set to zero and normalized against a convolution in which missing values are set to zero and nonmissing values are set to 1 . In this way, within a column with missing data, information from surrounding grid points informs the gridded model state within the void. Zonal and meridional (model background) wind fields use the same method but with three recursions instead of eight.

The geographic distribution of observations varies by observed variable (Fig. 1). Joaquin developed in the Caribbean Sea and recurved into the western Atlantic Ocean, consistently staying $10^{\circ}-15^{\circ}$ longitude east of the 
a

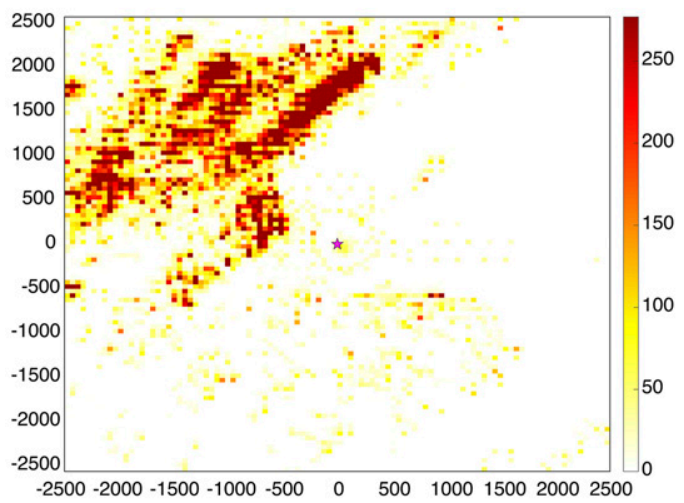

C

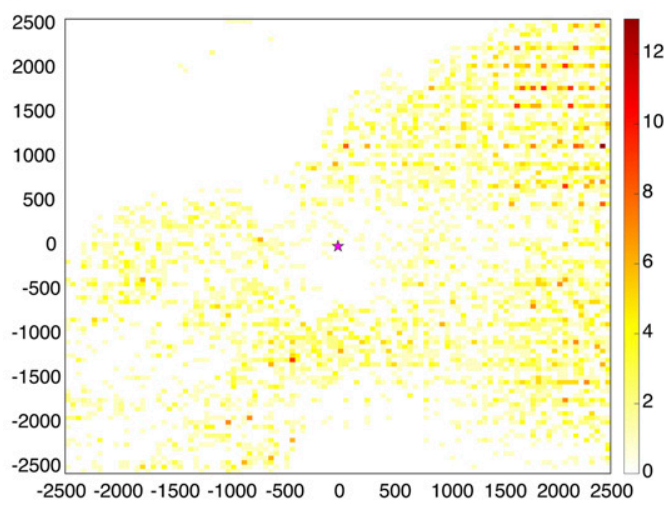

b

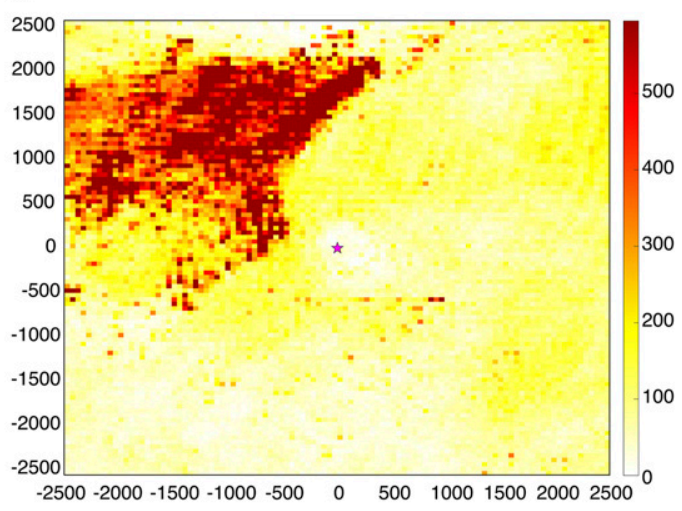

d

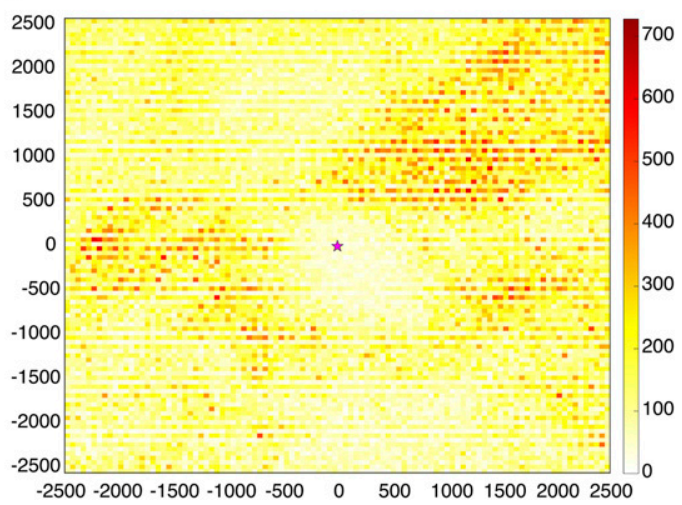

FIG. 1. Density of observations in the column between 980 and $200 \mathrm{hPa}$ in storm-centered composite of Hurricane Joaquin (2015) for (a) temperature observations, (b) wind observations, (c) precipitable water observations, and (d) brightness temperature observations (not constrained between pressure levels). The star in the center represents the TC center.

U.S. coast. A high density of in situ observations of temperature and winds over the continental United States is visible northwest of the TC center in the composite, while observations over the ocean are far less numerous, and a dearth of observations is visible near the TC center itself (Figs. 1a,b). Total-column precipitable water observations are sparse to the northwest of the TC center and more evenly distributed over the ocean (Fig. 1c). Brightness temperature observations are more evenly distributed across the entire domain than any other observations (Fig. 1d). The geographic distribution of observations is important to consider when evaluating the geographic distribution of observation impact, since the collocation of high impact and a synoptic-scale feature of the atmosphere can be artificially enhanced or weakened by differences in where particular observed variables sample the atmosphere.

Compositing of observation impact across time serves a useful purpose in identifying observations that routinely impact the forecast, which can be useful for identifying regions of the model background that are routinely influenced by assimilation of observations to provoke a consistent impact in the forecast and identifying relationships between model bias (or possibly observation bias) and the forecast. The presence of a consistent, spatially coherent observation impact across several analysis cycles is a symptom of some persistent and spatially coherent disagreement between the model background and observations, which can be caused by either a model background bias or an observation bias. In Hoover and Langland (2017), a warm bias in the model background at high latitudes was related to the consistent, large impact of high-latitude AMVs on the 24-h forecast error through thermal wind balance. In Cummings and Smedstad (2014), monthly averages of impact from sea surface temperature observations retrieved from GOES-13 satellite data were found to provide detrimental impact (i.e., increased forecast error) when observations were assimilated near the periphery of the observed disk. These detrimental impacts were suspected to be caused by high zenith angles creating longer atmospheric path lengths to reach the sea 
surface, resulting in additional noise in the sea surface temperature retrieval from aerosol contamination and increased total-column water vapor, creating larger errors in these periphery-of-disk observations and degrading the forecast.

The goal of this study is to similarly seek out relationships in the interaction between model bias, observations, and the TC intensity forecast by using time compositing of observation impact in a geographic space centered on the TC.

\section{Results}

\section{a. Impact of observations by observation type}

One of the most common evaluations of observation impact is summed observation impact by observation type. This evaluation can be performed either as a sum across all observations of a given type or normalized by the total number of observations (i.e., impact per observation). In previous studies, the response function defines a forecast error norm, in which positive (negative) impacts are considered detrimental (beneficial). For a response function representing the forecast intensity of a TC, a distinction between detrimental and beneficial impacts cannot be made a priori. As a result, a further distinction can be made between the summed observation impact and the summed absolute value of observation impact, the latter representing the total impact of the observation type on the TC, whether that impact is positive or negative. These can be computed on a sum-total or a per-observation basis, creating four observation-impact evaluations by observation type: total impact, per-observation impact, total absolute impact, and per-observation absolute impact.

On a per-observation basis, synthetic observations derived from TC reconnaissance (Goerss and Jeffries 1994) impose the largest absolute impact (Fig. 2d), as well as the largest consistently negative (i.e., intensifying) impact among all observation types (Fig. 2c). Previous research using a traditional data impact study framework has shown that these synthetic observations are assumed to have small errors and have a significant impact on the TC track forecast (Reynolds et al. 2013). Synthetic TC observations have the largest impact on the 12 -h forecast with impact tapering off as the forecast length is increased, with the impact on Joaquin decreasing by about $35 \%$ (Fig. $2 \mathrm{a}$ ) between the $12-$ and 48 -h forecasts. This is despite the fact that almost universally the absolute impact increases in magnitude for each observation type as the forecast length increases (Fig. 2b). It can be concluded that the impact of synthetic TC observations grows in magnitude but is more evenly distributed between positive and negative impacts as the forecast length increases. This could be due, for example, to the forecast TC intensity being less strongly controlled by the initial intensity and structure as defined by the synthetic observations and more strongly controlled by evolving interactions with the environment as the forecast length increases. Impact by observation type is distributed almost equally between raising and lowering the TC intensity in much the same way that it has been found to be distributed almost equally between raising and lowering the 24-h forecast error (Gelaro et al. 2010), with the total impact by observation type being positive or negative based on a relatively small margin.

The largest absolute impact for Joaquin comes from in situ aircraft observations from the U.S. Meteorological Data Collection and Reporting System (MDCRS), a U.S. branch of the World Meteorological Organization's Aircraft Meteorological Data Relay (AMDAR) program. These observations include winds, temperatures, and moisture observations collected both at flight level and in profiles when aircraft are ascending and descending at airports. AMDAR observations have been shown to contribute substantially to short-range (3-12 h) regional forecasts over the continental United States and to global forecasts out to $48 \mathrm{~h}$ (Petersen 2016), with aircraft moisture observations expressing the largest observation impact among all U.S. in situ moisture observations in 24-h NAVGEM forecasts (Petersen et al. 2016). Aircraft observations from the Tropospheric Airborne Meteorological Data Reporting (TAMDAR) system have been shown to be a major contributor to reducing the 24-h forecast error over the continental United States in adjoint-based observation-impact experiments with the Weather Research and Forecasting Model (Zhang et al. 2015). The absolute observation impact of MDCRS observations on Joaquin's intensity forecast is roughly commensurate with the number of observations for each variable: wind observations command roughly $75 \%$ of the total MDCRS observations and contributes about $81 \%$ of the total absolute observation impact from MDCRS; temperature observations make up roughly $21 \%$ of the observations and contribute roughly $19 \%$ of the impact. MDCRS moisture observations, while making up roughly $4 \%$ of the total MDCRS observations, only contribute roughly $0.3 \%$ of MDCRS absolute observation impact. The small impact of moisture observations is likely a by-product of the limited moisture physics available to the adjoint model, and likewise represents a limitation of the observation impact to properly identify the impact of moisture observations. It is also possible that the impact of moisture observations is small because of the choice of response function.

Previous studies computing the impact of observations on the 24-h global forecast error reduction have shown 
a

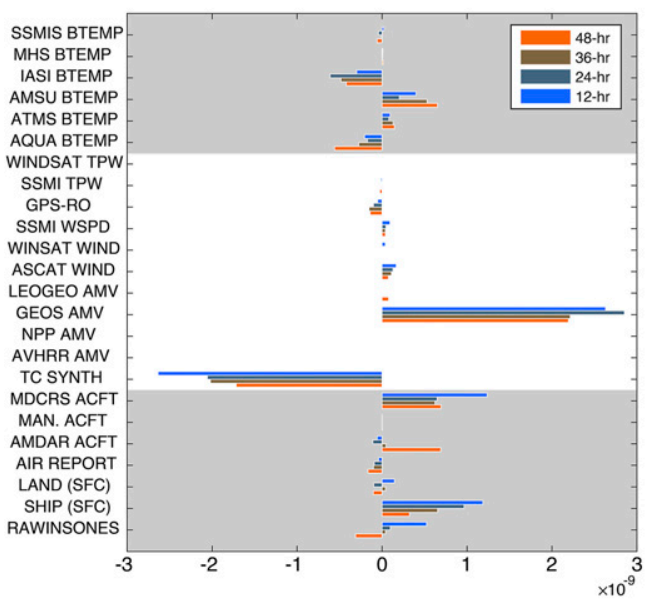

C

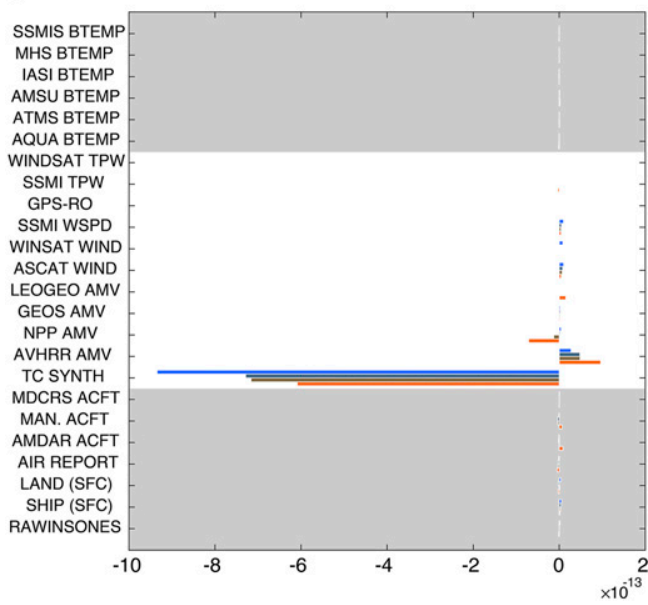

b

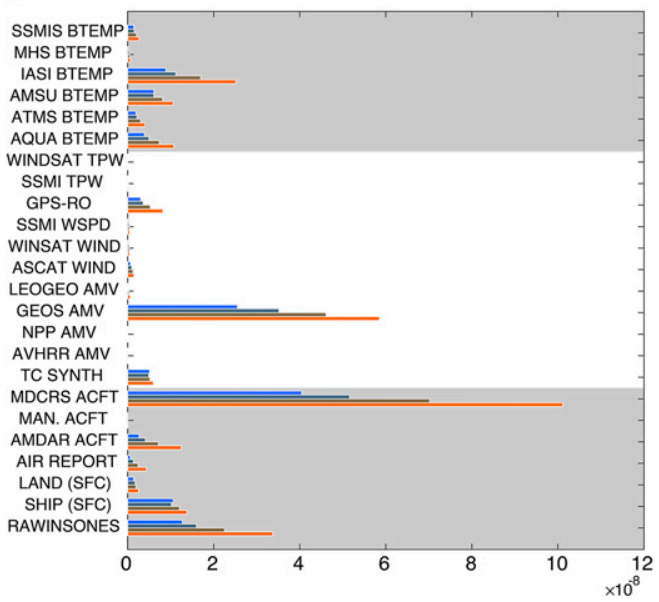

d

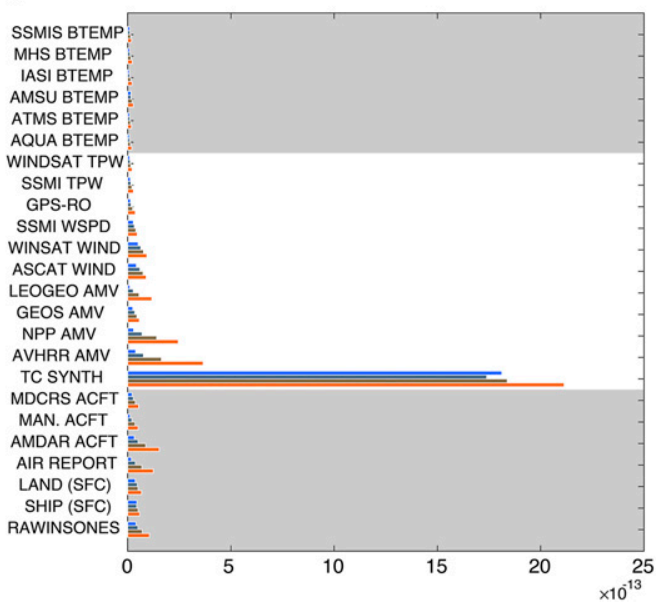

FIG. 2. Observation impact by observation type for Hurricane Joaquin. Observation impact is evaluated by (a) total impact, (b) total absolute impact, (c) per-observation impact, and (d) per-observation absolute impact. Observation impact is provided for 12-, 24-, 36-, and 48-h forecasts for all observations included in storm-centered composites, normalized by the size of the response function box. For each panel, the bars are separated into three zones that correspond to in situ observations (bottom), observations of wind and thermodynamic fields inferred or derived from remote sensing observations (middle), and brightness temperature observations from observed radiance (top).

that AMSU-A radiance observations are a leading contributor to reducing forecast error (Gelaro et al. 2010), but AMSU-A radiances are a small contributor to the TC intensity forecast, with only a roughly $4 \%$ contribution to the total absolute impact from AMSU-A and 18\% contribution from radiance observations from Aqua, Advanced Technology Microwave Sounder (ATMS), AMSU-A, IASI, Microwave Humidity Sounding (MHS), and SSMIS collectively. Assimilation of satellite-derived wind observations from geostationary satellites have been shown to improve the track forecast of tropical cyclones in both regional NWP models (Leslie et al. 1998) and global NWP models (Goerss 2009; Langland et al. 2009). Some improvement to intensity forecasts has also been identified (e.g., Osuri et al. 2012). These winds contribute $21 \%$ of the total absolute impact, predominantly contributing to an increase in the response function, or a weakening of the $\mathrm{TC}$ in the forecast.

\section{b. Impact of upper-tropospheric wind observations}

Wind and temperature observations are separated into an upper-tropospheric (380-200 hPa) and a lowertropospheric (980-620 hPa) layer. Within each layer, the impact of observations is averaged in each column, and a mean model state for the column is computed for all observations existing within the column as discussed in section $3 \mathrm{~b}$. 
a

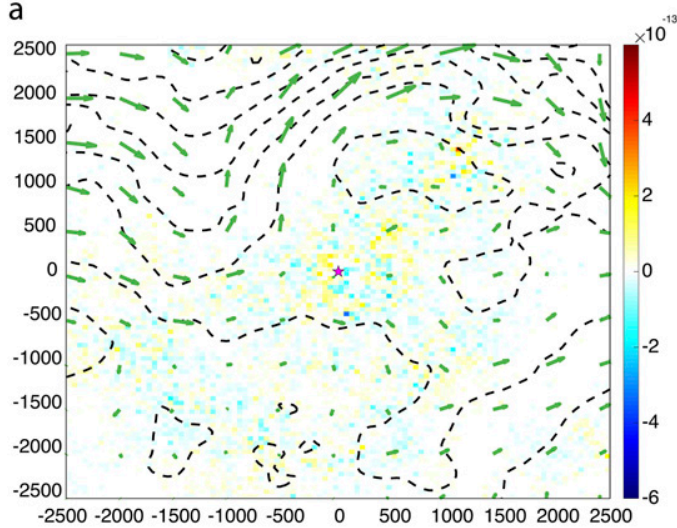

C

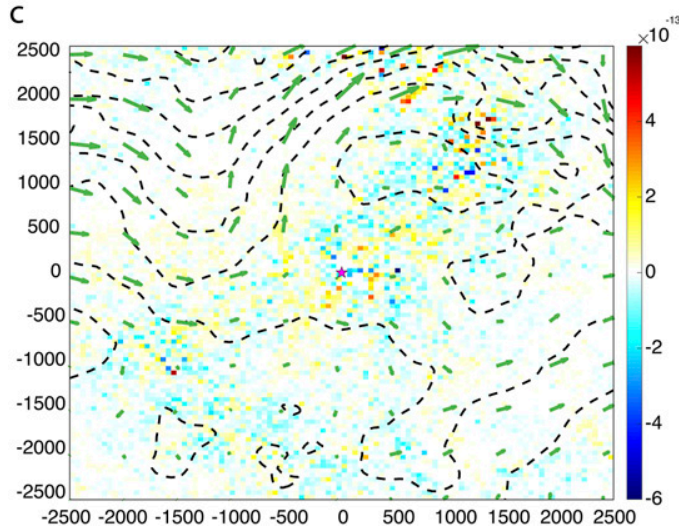

b

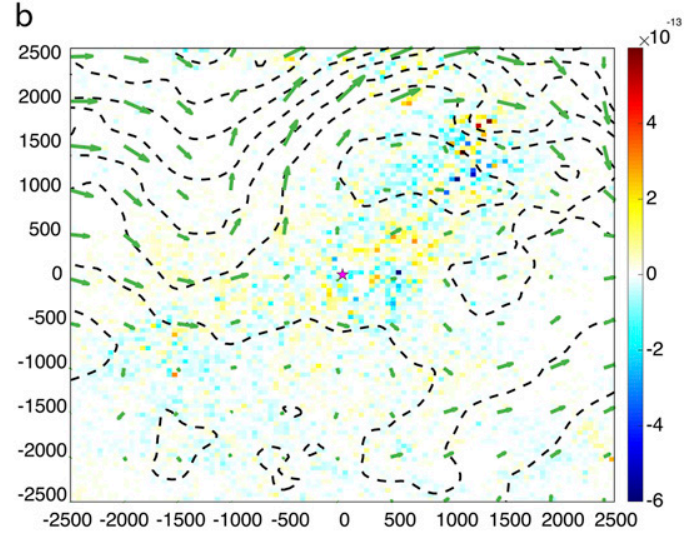

d

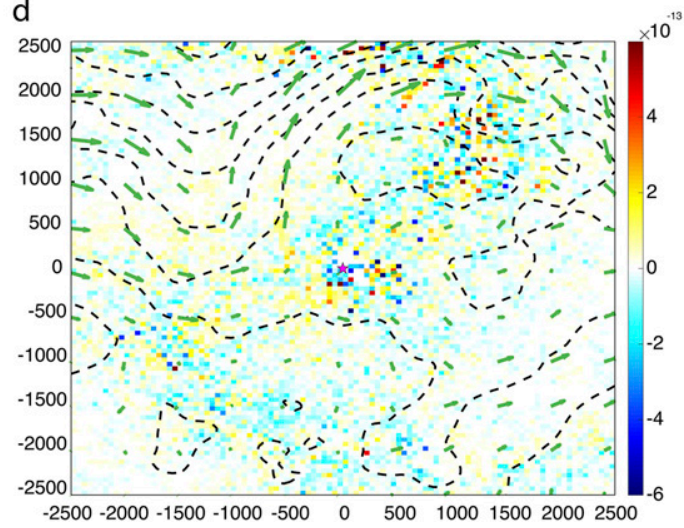

FIG. 3. Storm-centered composite of the impact of assimilated wind observations between 380 and $200 \mathrm{hPa}$ on the forecast intensity of Hurricane Joaquin in the (a) 12-, (b) 24-, (c) 36-, and (d) 48-h forecasts. Composite layer-average streamfunction is contoured, and composite layer-average wind is plotted as green vectors. The magenta star represents the latitude and longitude of the TC center in the composite.

The composite upper-tropospheric environment for Joaquin as described by the streamfunction includes a deep trough to the northwest and a ridge to the northeast, which is likely aided by Joaquin's outflow (Fig. 3). Impact of wind observations in this layer is larger for longer forecast lengths than for shorter forecast lengths; this is a characteristic that is consistent across all observation-impact analyses performed in this study. In general, regions of positive impact (i.e., columns where the average observation impact raises the forecast surface pressure in the response function box) tend to become more positive, and regions of negative impact tend to become more negative, as the forecast length increases.

Observation impact of wind observations on the 12-h forecast is concentrated to the near environment of the TC with little impact of observations sampling the trough to the northwest (Fig. 3a), and as the forecast length is increased to 24-h observation impact extends into observations sampling the outflow-enhanced ridge and the region south of the trough (Fig. 3b). Through the 36-h (Fig. 3c) and 48-h (Fig. 3d) forecast, observation impact extends further into regions to the south and southwest, as well as northwest into the high-speed flow north of the ridge. The region upstream of the trough axis also expresses observation impact, but the region around the trough axis itself expresses very little observation impact. Based on the sign of the impact, it is estimated that wind observations in the ridge and south of the TC have a tendency, on average, to intensify Joaquin at longer forecast lead times; wind observations sampling the base of the trough weaken Joaquin at longer forecast lead times, but these are not clearly defined features.

\section{c. Impact of upper-tropospheric temperature observations}

The composite impact of upper-tropospheric temperature observations shows sparse impact from temperature observations for short forecast lengths (Figs. 4a,b), and as the forecast length approaches $48 \mathrm{~h}$ (Figs. $4 \mathrm{c}, \mathrm{d}$ ) a consistent growth and intensification of negative observation impact 

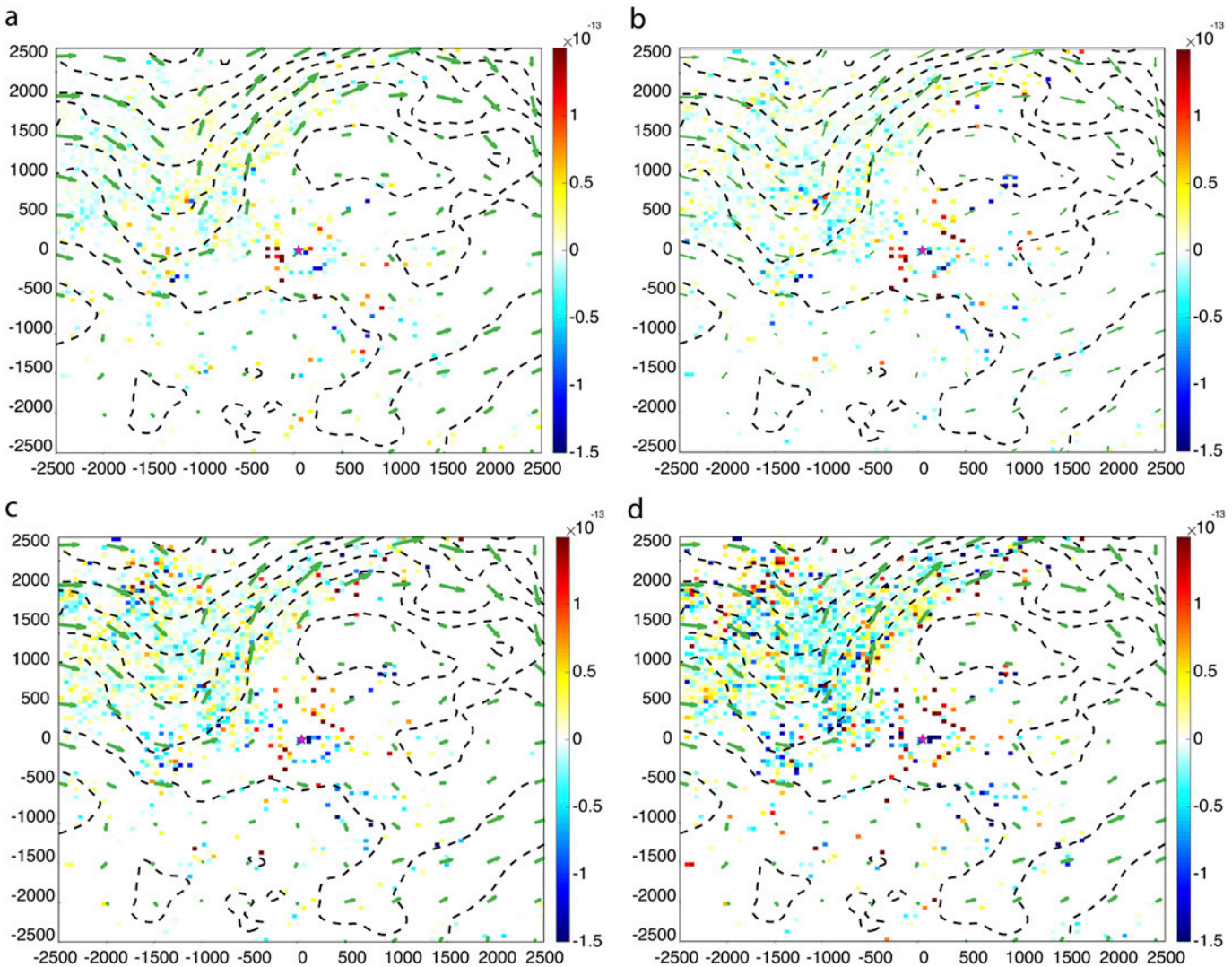

FIG. 4. As in Fig. 3, but for temperature.

(i.e., an increase in forecast intensity) develops within the trough northwest of the TC center. Observation impact near the TC center is high amplitude but sparse, and no significant impact develops within the outflowenhanced downstream ridge. Consistently negative impact occurs in and around the trough axis where wind observations displayed little impact (Fig. 3).

The composite temperature innovation relative to the model background, calculated as the difference between the observed temperature and the temperature in the model background state interpolated to the observation's location, is largest in the well-sampled northwest quadrant where the impacts are largest (Fig. 5). The innovation is predominantly positive within the region of the upstream trough where observation impact of temperature observations on the 36-48-h intensity forecast was found to be predominantly negative (Figs. 4c,d). A direct relationship between the composite temperature innovation and the observation impact on forecast intensity cannot be made absolutely clear through this technique, but it is noteworthy that Joaquin expresses enhanced divergent flow, represented by the gradient in model state velocity potential in the analysis-minusbackground difference, as a consequence of assimilating (all) observations. The composite velocity potential of the model background state expresses a strong gradient to the north of the TC center along the northern edge of the ridge (Fig. 5b); the composite velocity potential increment, representing the difference in velocity potential between the model analysis state and the model background state (Fig. 5d), expresses an enhancement of this gradient in the region where these high-impact temperature observations reside. This is coincident with an enhancement of ridging expressed as a positive streamfunction increment (Fig. 5c).

It is important to realize that, since observation impact can be either positive or negative, the compositing technique shown here expresses large values where observation impact is consistently of a particular sign. Therefore, regions of the composite expressing low amplitude can either represent low-amplitude impact from the existing observations or a more balanced distribution between negative and positive impacts. To address this, a composite was computed using the mean absolute value of the 48-h forecast observation impact (Fig. 6). The composite shows that high-amplitude impact of wind observations in the 48-h forecast is asymmetrically 
a

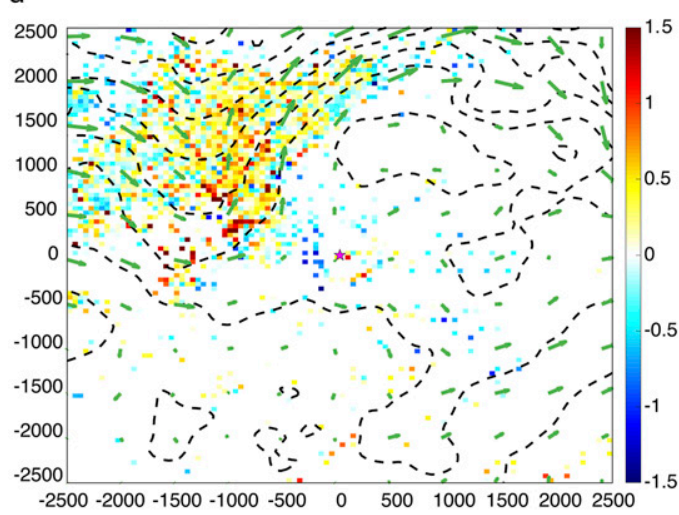

$\mathrm{C}$

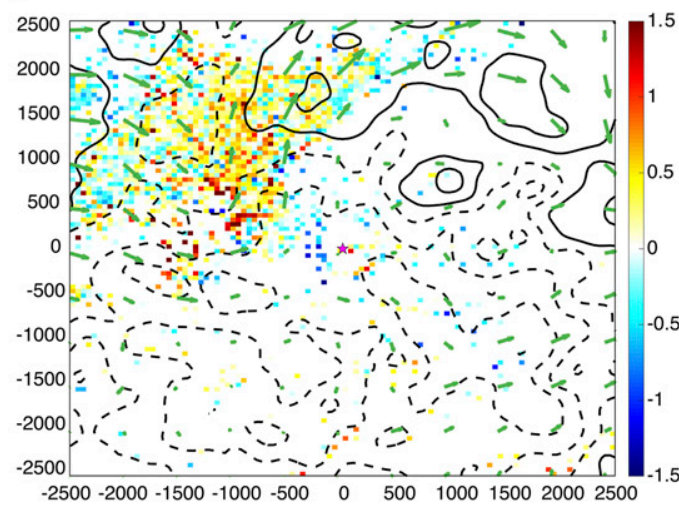

b

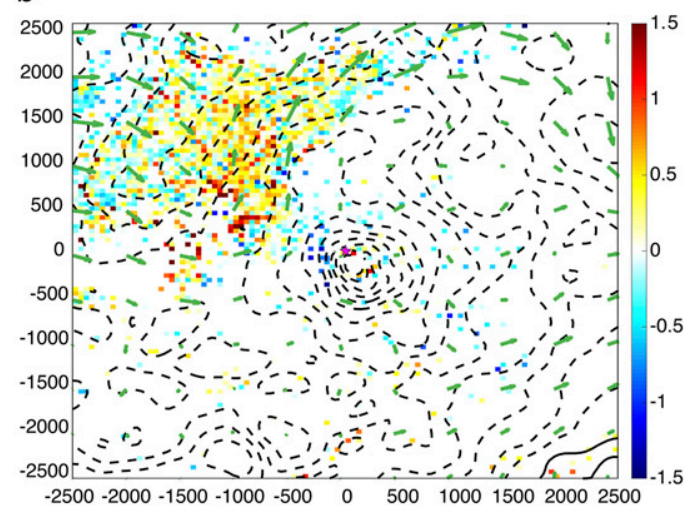

d

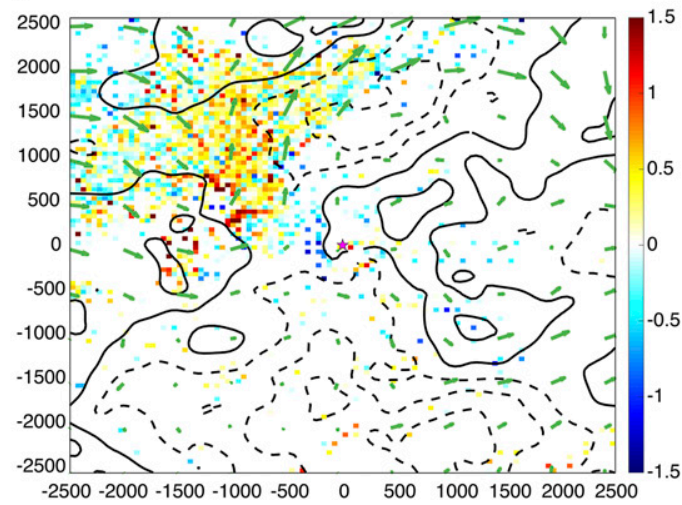

FIG. 5. Storm-centered composite of the layer-average innovation of temperature observations in the 380-200 hPa layer for hurricane Joaquin, contoured with (a) layer-average streamfunction, (b) layer-average velocity potential, (c) layer-average streamfunction model increment $\left(x_{a}-x_{b}\right)$, and (d) layer-average velocity potential model increment $\left(x_{a}-x_{b}\right)$. Dashed contours are negative, and composite layer-average wind is plotted as green vectors. The magenta star represents the latitude and longitude of the TC center in the composite.

distributed over a wide region south and east of the strongly sampled northwest quadrant (Fig. 6a), while high-amplitude impact of temperature observations appears to be restricted to the near-storm environment and the northwest quadrant where wind observations express less impact (Fig. 6b). These results imply that interactions between Joaquin and its remote environment are relevant to the forecast intensity at longer lead times. It is noteworthy that temperature observations demonstrate large composite observation impact in the well-sampled northwest quadrant of the composite, despite that this region of the continental United States, being highly sampled, is expected to have smaller analysis errors than more sparsely sampled regions over open ocean (Langland et al. 2008). This indicates, in the timecomposited average, that there are regular corrections to the model background during assimilation of uppertropospheric temperature observations that have a consistent impact on the forecast intensity of Joaquin in the 36-48-h forecast range, and that these regular corrections to the model background are not a product of poor in situ observational coverage over the ocean.

\section{d. Impact of lower-tropospheric wind and temperature observations}

As opposed to the observation impact of uppertropospheric wind and temperature observations, the observation impact of lower-tropospheric wind and temperature observations expresses less spatial coherence (spatial distribution and consistent sign and magnitude of impact). Total absolute observation impact from upper-tropospheric winds grows between the 12- and 48-h forecast lead times by a factor of 2.8 , and upper-tropospheric temperature observation impact grows by a factor of 4.2. By contrast, lower-tropospheric wind and temperature observation impact grows by only a factor of 2.2 and 2.3, respectively. However, observation impact of lower-tropospheric winds is consistently 1.2-1.6 times that of upper-tropospheric winds, and observation impact of lower-tropospheric temperature 

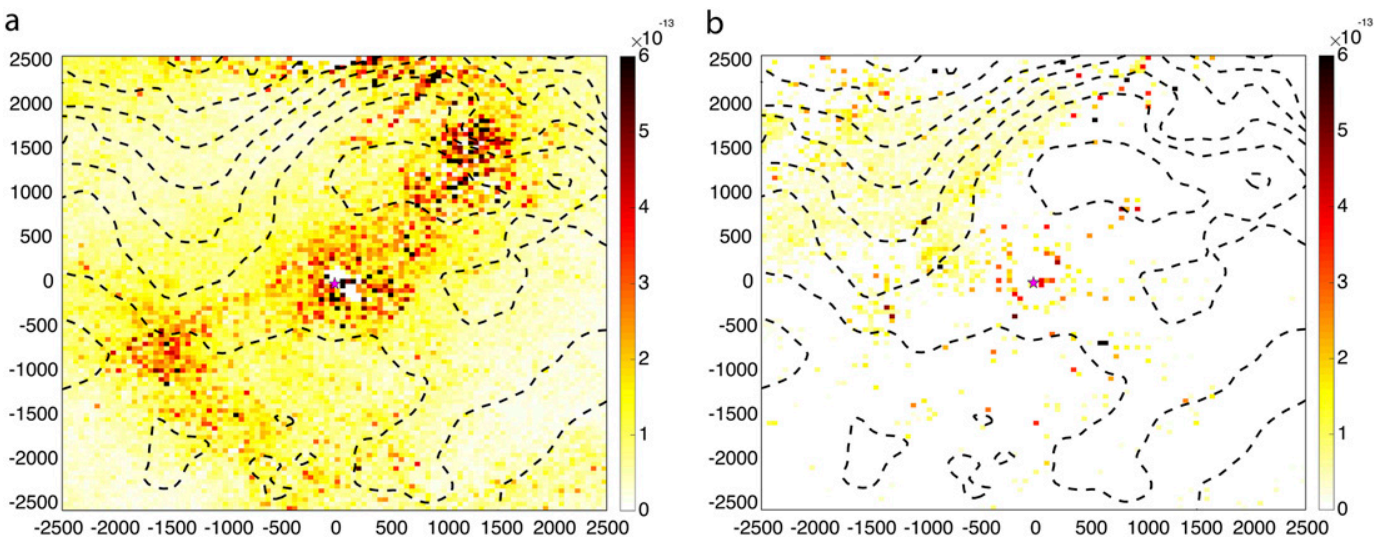

FIG. 6. Storm-centered composite of absolute value of observation impact from (a) wind and (b) temperature observations in the 380-200 hPa layer on the 48-h intensity forecast for Hurricane Joaquin. Composite layer-average streamfunction is contoured. The magenta star represents the latitude and longitude of the TC center in the composite. Observation impact is computed as per observation (i.e., normalized by number of observations).

observations is 5.6-10 times as large. This indicates that lower-tropospheric wind and temperatures consistently exert a significant influence on the forecast intensity of Joaquin regardless of forecast length, while the impact of upper-tropospheric wind and temperature observations are small in the 12-h forecast but increase with increasing forecast length. Since observation impact of winds in the upper troposphere tends to appear in the near- and far-storm environment, it is speculated that the increase in impact with forecast length in the upper troposphere is due to modulation of the TC's environment and features of the large-scale flow that exert a greater influence on the TC intensity forecast for longer forecast lead times.

The composite lower-tropospheric streamfunction environment around Joaquin (Fig. 7) is typified by a broad trough immediately to its west and an anticyclone to the northeast. Observation impact is strongly concentrated near the TC center for both lower-tropospheric wind and temperature observations. There is growth in negative observation impact of winds in the high-velocity wind between the TC and the anticyclone at longer forecast lengths (Fig. 7), but otherwise very little spatial coherence of any kind exists, with positive and negative observation impact of winds distributed seemingly randomly within the small radius of the TC center in which they express influence. Likewise, large impact of lower-tropospheric temperature observations is constrained to a small region around the TC, with the exception of some sparse regions of impact to the northeast for 36- and 48-h forecasts (Fig. 8).

If observations were correcting purely random errors in the model background, as is sometimes assumed in simplified data assimilation theory, the resulting innovations would likewise be distributed randomly, and the product of the innovation and sensitivity gradient would lack spatial coherence. The presence of spatial coherence in the observation impact therefore implies the presence of spatially coherent error in the model background that is being corrected by the data assimilation process. The same is true of systemic analysis increments for the same reason (Dee 2005), although in the present study the spatial coherence of the observation impact is focused specifically on spatially coherent errors in the model background that have an impact on the TC intensity forecast. The spatially coherent model background error in a time-averaged composite can be interpreted as an error of bias. Biases exist in the model background in the upper troposphere, especially in the temperature field within the upstream trough, that produce analysis increments during data assimilation that translate to intensification of the TC in the forecast at 36-48-h forecast lengths. By contrast, there is no evidence in these composites of significant model-background biases in lower-tropospheric wind and temperatures that consistently produce analysis increments that intensify or weaken TCs in the forecast, though observation impacts in the lower troposphere are large.

\section{e. Observation impact of radiance and precipitable water observations}

Both radiance and precipitable water are satellitederived measurements that sample throughout the atmospheric column. Storm-centered composites are computed across all available radiance channels from SSMI, IASI, ATMS, AMSU, and MHS platforms, and precipitable water observations derived from SSMI and WindSat. The composited observation impact is plotted with the model background dewpoint depression averaged from 980 to $380 \mathrm{hPa}$, representing regions of deep-layer-mean saturation in the environment. 
a

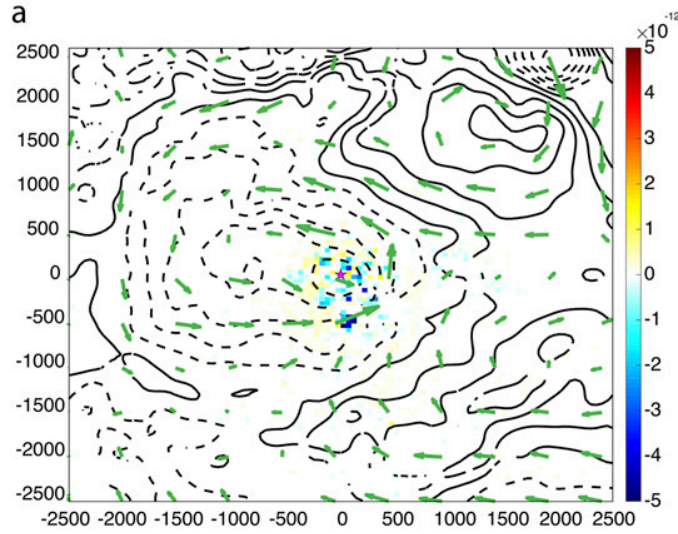

C

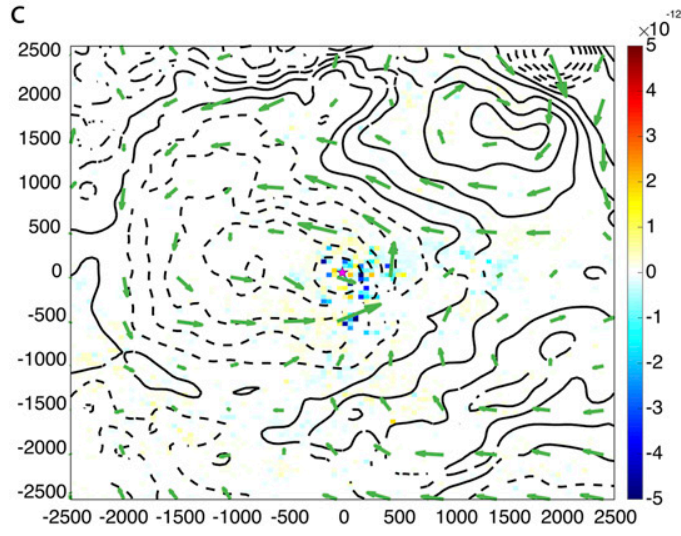

b

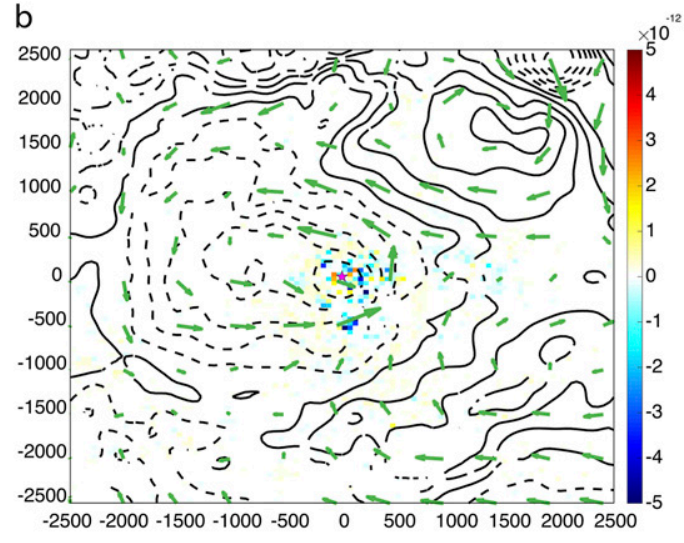

d

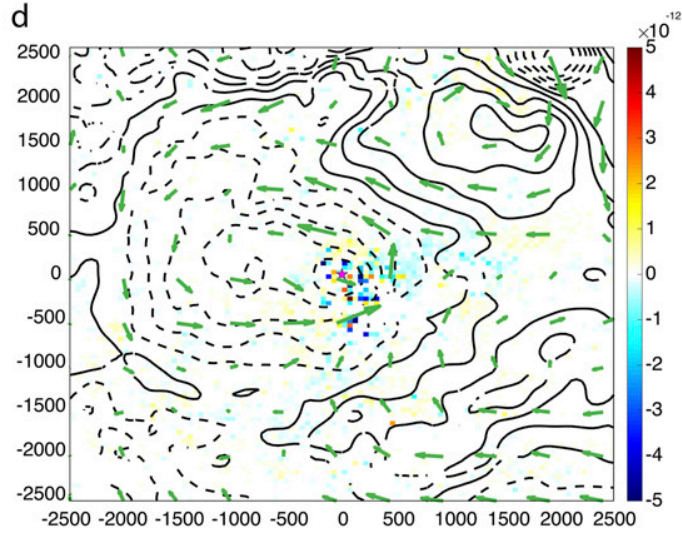

FIG. 7. Storm-centered composite of the impact of assimilated wind observations between 620 and $980 \mathrm{hPa}$ on the forecast intensity of Hurricane Joaquin in the (a) 12-, (b) 24-, (c) 36-, and (d) 48-h forecasts. Composite layeraverage streamfunction is contoured, and composite layer-average wind is plotted as green vectors. The magenta star represents the latitude and longitude of the TC center in the composite.

Composite observation impact of brightness temperatures derived from radiance observations (Fig. 9) are strongly positive directly over the TC and weakly negative within the near environment. The magnitude of the observation impact is also largest near the TC and decays with distance from the TC center but displays no clear relationship to the moisture content of the environment as described by the layer-average dewpoint depression. By contrast, the composite observation impact of precipitable water is small in regions of low dewpoint depression (including the near environment of the TC, where observations of precipitable water are sparse; see Fig. 1c) and large in regions of large gradients in dewpoint depression adjacent to the high dewpoint depression regions to the north and northeast of the TC (Fig. 10). Observation impact is predominantly negative, indicating that precipitable water observations tend to intensify the forecast TC. The relationship between observation impact and precipitable water innovation unsurprisingly favors intensification or weakening of the forecast TC when innovations are positive or negative, respectively. The distribution of precipitable water observation impact is skewed toward intensification (i.e., negative impact) for observations with positive innovations, while the distribution is skewed toward weakening (i.e., positive impact) for those with negative innovations and there is no clear signal in the amount of skewness as a function of forecast length (not shown). It can be inferred that there are biases in the model background precipitable water that favor drier conditions, which translate into weaker TC intensity forecasts as the dry bias is ingested into the TC from the north and northeast, and these biases are mitigated through assimilation of total precipitable water observations.

\section{f. Observation impact of reconnaissance dropwinsondes relative to routine observations}

Targeted observations are often deployed within a tropical cyclone and its immediate environment for the explicit purpose of improving the track or intensity forecast. Observations such as dropwindsondes are deployed from reconnaissance aircraft, and the impact 
a

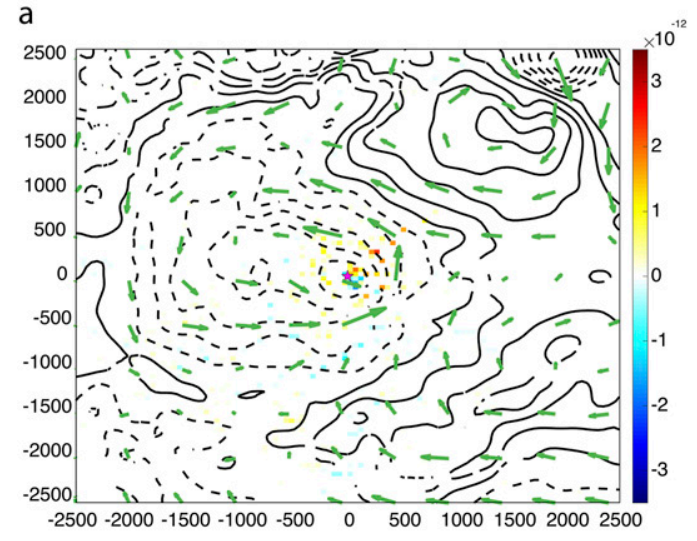

c

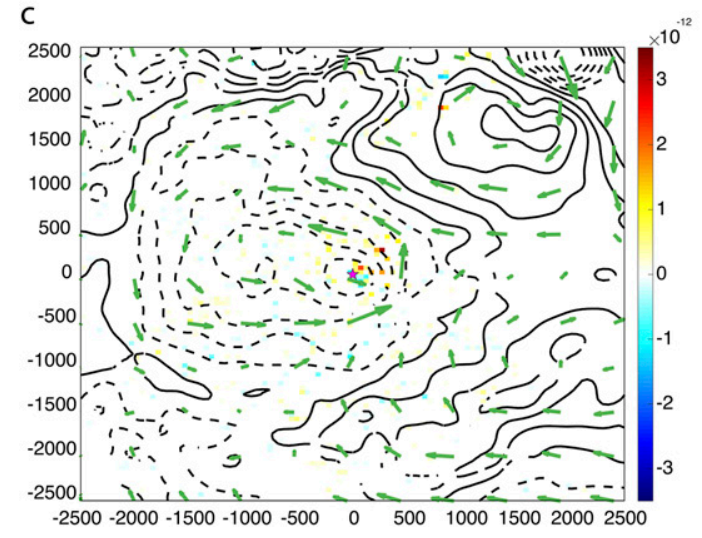

b

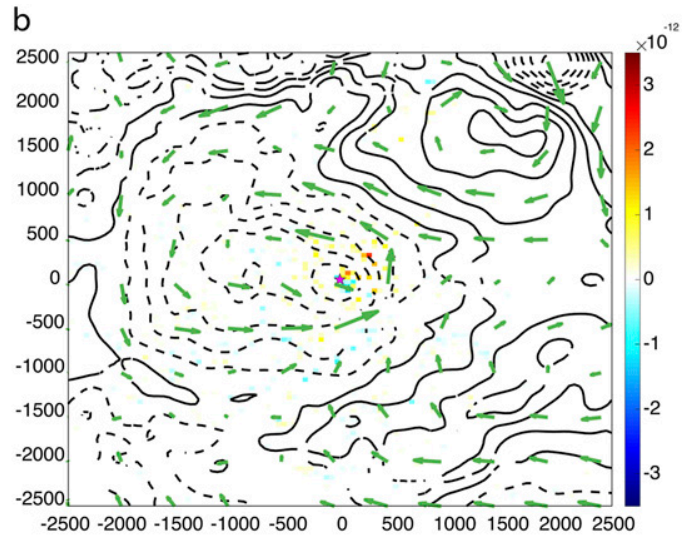

d

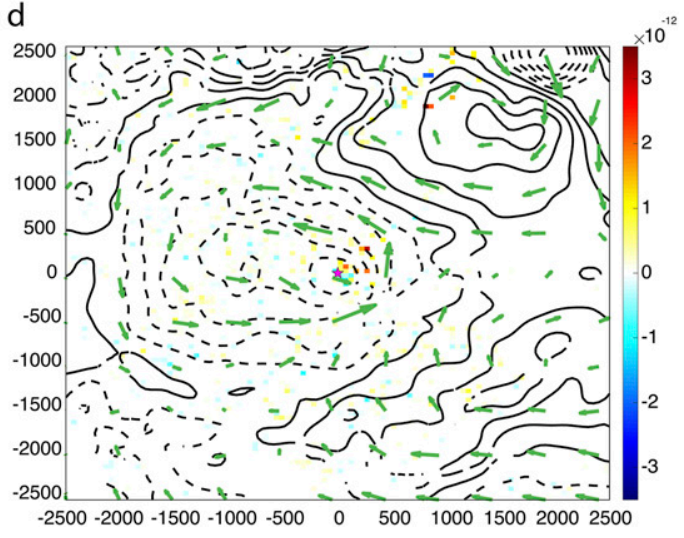

FIG. 8. As in Fig. 7, but for temperature.

of those observations is computed in an OSE framework (e.g., Burpee et al. 1996; Aberson and Franklin 1999; Wu et al. 2007; Aberson 2011; Chou et al. 2011; Majumdar et al. 2013). Impacts on TC track indicate statistically significant improvement within the first $72 \mathrm{~h}$ of the forecast, and generally positive impact on intensity with results depending on case and choice of model (e.g., Aberson 2010). As with any OSE study, direct comparison between impact of observations is made difficult by the redistribution of weights on the rest of the observations when a set of observations is included or excluded. In addition, as can be seen in the results presented in this study, observation impact can be distributed between positive and negative impacts on intensity for any subset of observations, resulting in large cancellations that may be mistaken for low sensitivity of the forecast to the observations.

Hurricane Matthew (2016) was a unique case in which the TC remained just off the coast of the United States, not quite making landfall for a significant portion of its life. National Hurricane Center best-track data identify two periods between 1200 UTC 6 and 1800 UTC 8 October 2016 during which Matthew's center intersected land - once at 0000 UTC 7 October when Matthew passed over Grand Bahama near Freeport, and again on 1500 UTC 8 October when Matthew made landfall again roughly 30 miles north of Charleston, South Carolina. During this time, reconnaissance dropwindsonde observations were collected as Matthew remained close to the coastlines of Florida, Georgia, and South Carolina and were ingested into the NAVDAS-AR to produce initial (analysis) states for the NAVGEM model. The model was cycled throughout the 1200 UTC 6-1800 UTC 8 October 2016 period, using the same model configuration that was used to compute the impact of observations on the TC intensity forecast for Joaquin.

The impact of "sonde" observations on Matthew is compared between those sondes that originate from routine rawinsonde launches and those that were collected from reconnaissance. The routine rawinsondes are filtered by removing all observations outside a radius of $1100 \mathrm{~km}$ from the TC center and pressures below $69 \mathrm{hPa}$, which represent the maximum-radius and minimumpressure bounds of the reconnaissance observations. After filtering the routine rawinsondes, reconnaissance observations compose roughly $40 \%$ of the wind observations, $33 \%$ of the temperature observations, and 

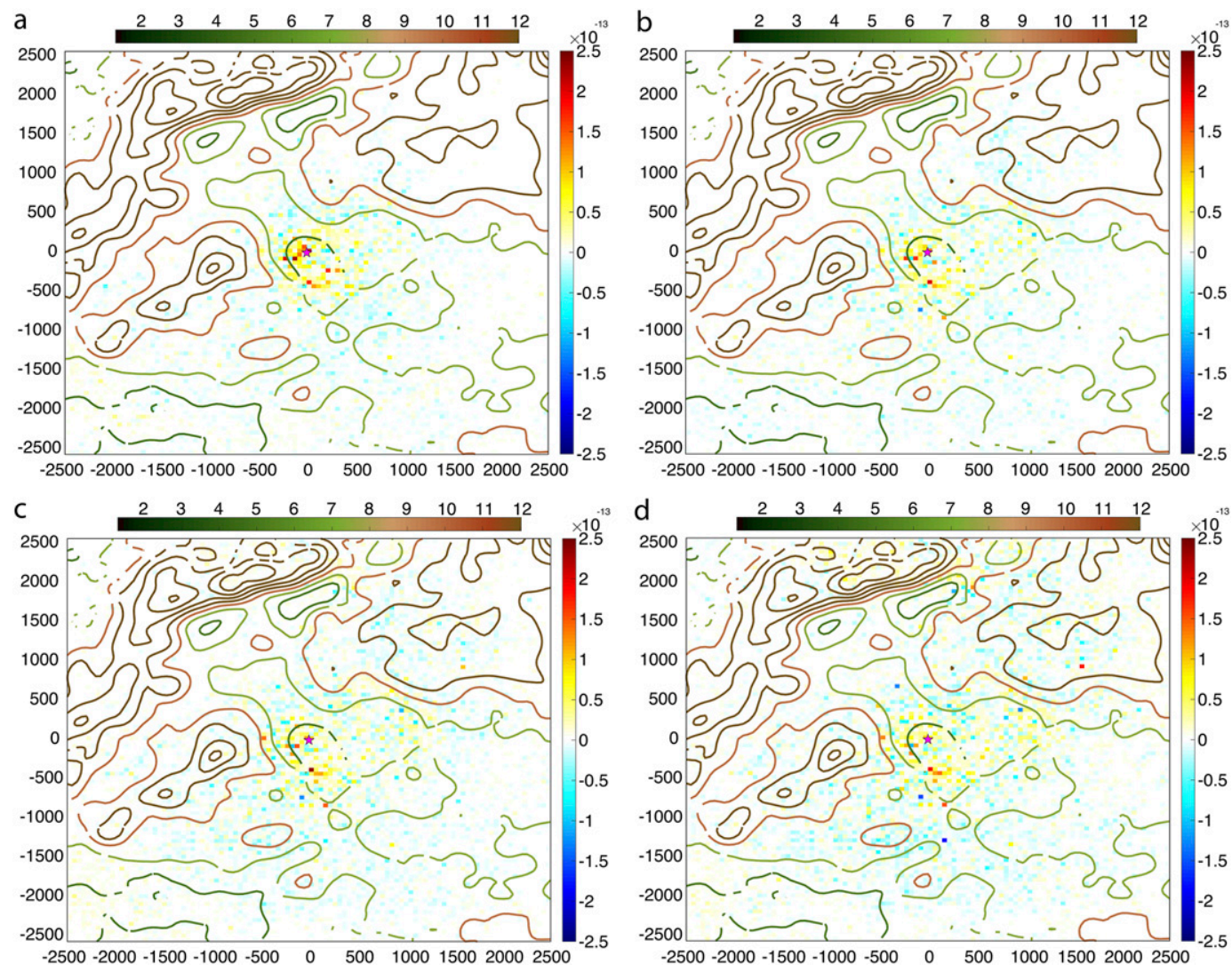

FIG. 9. Storm-centered composite of the impact of assimilated brightness temperature observations on the forecast intensity of Hurricane Joaquin in the (a) 12-, (b) 24-, (c) 36-, and (d) 48-h forecasts. Composite 980-380-hPa layeraverage dewpoint depression is color contoured (top color bar in each panel). The magenta star represents the latitude and longitude of the TC center in the composite.

$37 \%$ of the moisture observations. In total, there are 15096 wind observations, 9489 temperature observations, and 7063 moisture observations available for comparison. These are referred to as dropsonde and "nearby" rawinsonde observations.

The distribution of observation impact for reconnaissance observations is separated into 200 bins, computed separately for the 12-, 24-, 36-, and 48-h forecasts and for each of the observation variables (temperature, wind, and relative humidity). The distribution of positive observation impact and negative observation impact is plotted in log space (Fig. 11), expressing a quasi-linear distribution in the space, representative of a power-law distribution. For each distribution of reconnaissance observations, 10000 Monte Carlo resamplings are performed on the available routine observations, generating $10000 \mathrm{log}$-space distributions. The distribution of reconnaissance observation impact is compared with the mean of distributions from the resampled routine observation impact and a range around the mean defined by two standard deviations. This comparison should identify whether dropsonde observations provide information to the intensity forecast, above and beyond what is supplied by the routine observation network, in a case where the Hurricane is very close to the coastal routine observation network.

Observation impact from reconnaissance observations expresses a distribution of larger impacts than the nearby routine observations for wind and temperature observations at 12- and 48-h forecast lead times (Fig. 11), with a trend in the distributions toward less exceptional impact from reconnaissance observations with increasing forecast lead time. For temperature observations and wind observations, reconnaissance provides fewer low-impact and more high-impact observations than 2 standard deviations above the mean for nearby routine observations across nearly the entire sampled distribution for the 12-h forecast (Fig. 11a). This can be interpreted as a statistically significant increase in observation impact of reconnaissance observations relative to the observation impact of nearby rawinsonde observations within the same maximum radius and depth of the 

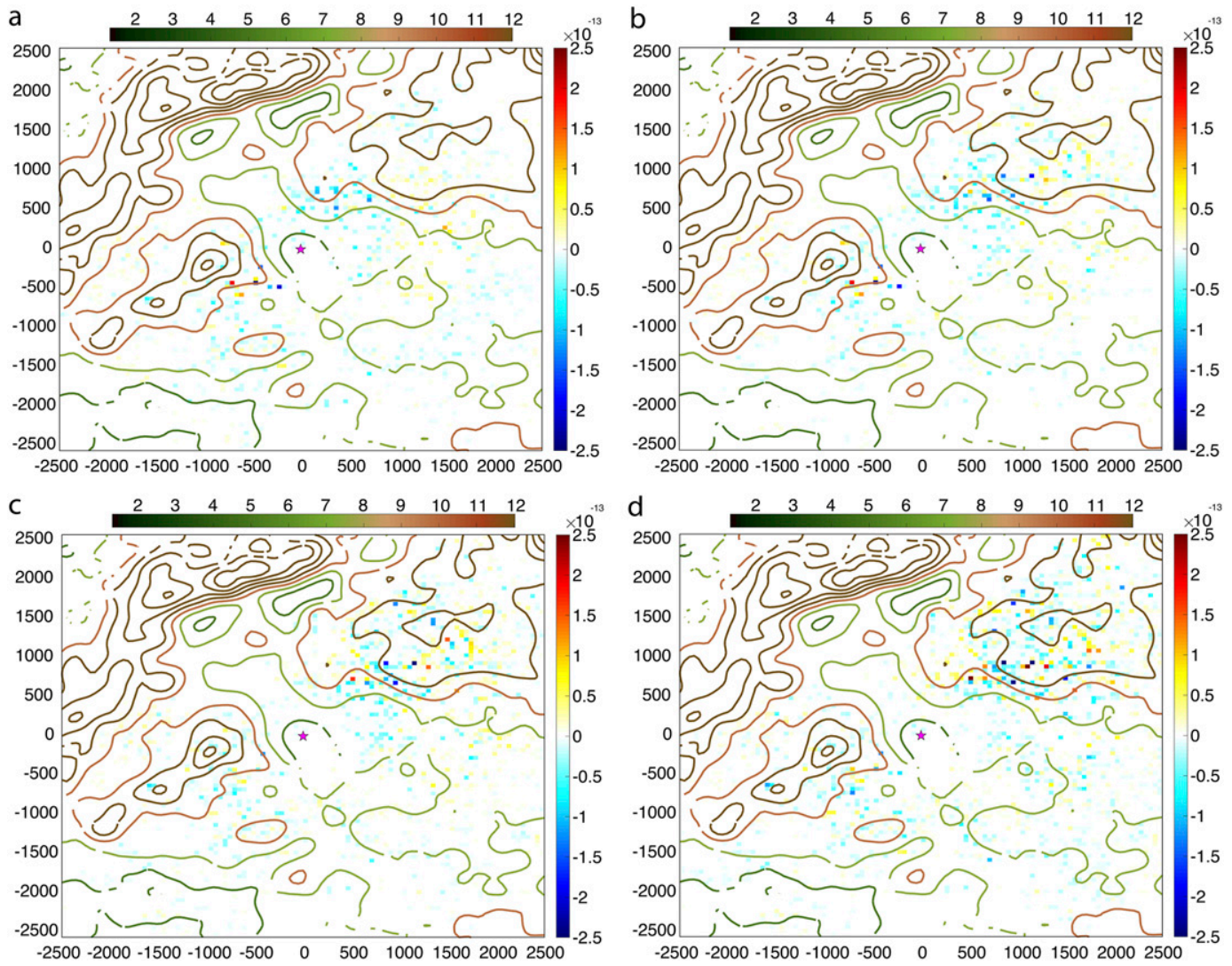

FIG. 10. As in Fig. 9, but for precipitable water.

troposphere. By contrast, the reconnaissance relative humidity observation impact is far less statistically distinguishable from that of routine observations for most of the sampled distribution. The impact of dropwindsonde observations on the 48-h forecast displays less statistical significance (Fig. 11b), with dropwindsonde temperature and wind observations being less distinct from conventional observations while the change in significance of impact of dropwindsonde relative humidity observations between 12- and 48-h forecasts is less clear. Despite these changes, the distributions for 48-h forecasts retain much of the same qualitative trend toward fewer low-impact observations and more high-impact observations relative to nearby rawinsonde observations.

The exceptionally high impact of reconnaissance dropwindsondes as compared with the nearby rawinsondes can only be attributable to a few possible sources. The dropwindsondes must sample regions of higher error and/or larger dynamical relevance to forecast TC intensity, or the dropwindsondes must be of higher quality than rawinsondes, or dropwindsondes must be assimilated differently from rawinsondes in such a way as to allow the dropwindsondes to express larger impact (e.g., lower assumed observational errors allowing for larger observational weighting coefficients during assimilation). Differences in assumed observational errors are less than $3 \%$ for all variables, possibly owing to identical error profiles but minor differences in pressure levels at which dropwindsondes and nearby rawinsondes sample the atmosphere. Mean (absolute) innovations for temperature and moisture observations from dropwindsondes vary by only $1 \%-5 \%$ relative to those from rawinsondes, indicating that temperature and moisture observations sample regions of the atmosphere of roughly the same certainty in the model background. However, mean (absolute) innovations from wind observations are $30 \%$ larger for dropwindsondes as compared with nearby rawinsondes, indicating that the dropwindsonde observations sample regions with less certainty in the background wind field than do nearby rawinsondes.

In addition, the mean (absolute) sensitivity of the 12-h forecast to observations, computed as the observation impact normalized by the innovation, is $130 \%$ higher for temperature dropwindsondes than for nearby rawinsondes, $85 \%$ higher for wind observations, and $130 \%$ higher for moisture observations; dropwindsondes are therefore clearly sampling regions of higher dynamical significance to the forecast than nearby 

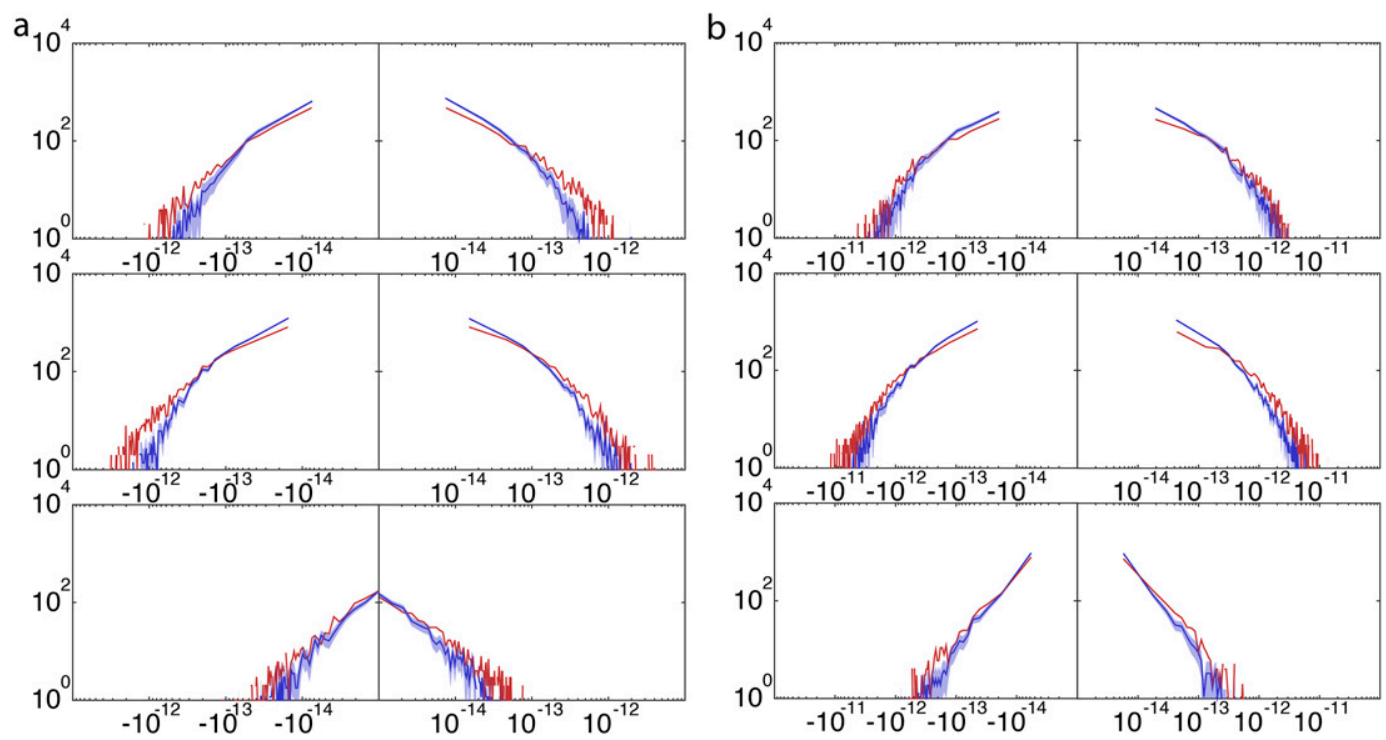

FIG. 11. Distribution of observation impact of (top) temperature observations, (middle) wind observations, and (bottom) moisture observations in relative humidity space on the intensity forecast of Hurricane Matthew (2016). Impact is shown for the (a) 12- and (b) the 48-h forecasts. The red lines indicate the impact of reconnaissance dropsonde observations. Impact of nearby rawinsonde observations is provided in blue; the distribution of impacts from rawinsonde is defined by a 10000-member Monte Carlo resampling of available observations, with the mean represented by the dark-blue line and 2 standard deviations from the mean represented by the light-blue shading. For each plot, the distribution of positive impacts and distribution of negative impacts is computed separately, with negative impacts multiplied by -1 for the purposes of computed a log-space distribution. Note the $x$ axis (observation impact) reversing direction across the middle of each plot.

rawinsondes, even before accounting for the size of their innovations.

Dropwindsondes are distributed both in the Gulf of Mexico to the west of Florida and the Caribbean and along the Gulf Stream in the tropical and subtropical Atlantic to the east of Florida, as far north as North Carolina (Fig. 12). Nearby rawinsondes are largely confined to the southeastern continental United States with a few stations in the Caribbean. The impact of dropwindsonde temperature (Fig. 12a) and wind observations (Fig. 12b) shows significant impact from observations just off the east coast within the path of Matthew, with smaller impacts from temperature observations upstream or downstream. Wind observations, containing the union of high-sensitivity and large innovations, express the largest individual impacts. Moisture observations (Fig. 12c) show the smallest impacts with little dependence on geographic location. Small impacts from moisture observations are likely influenced by the NAVGEM adjoint's limited moisture physics, and is likely producing a muted sensitivity to the initial moisture field. In other studies utilizing adjoint models with more sophisticated moisture physics, the forecast intensity of tropical and severe extratropical cyclones is more sensitive to the moisture field than the wind field (e.g., Doyle et al. 2012, 2014), and ensemble-based sensitivity studies making use of the full-physics nonlinear NWP model to extract sensitivity information also elevate the importance of initial moisture perturbations (Brown and Hakim 2015). While cross-variable comparisons may be subject to artifacts caused by the simplified physics of the adjoint, comparisons of observations within a variable, such as comparisons between dropwindsonde and nearby rawinsonde observations of the same variable, may be more reliable.

\section{Conclusions}

Adjoint-derived observation impact is a powerful tool for estimating the impact of individual observations on the forecast, and while this technique has been almost exclusively applied to response functions defining the domain-wide forecast error, it is possible to apply this technique to more phenomena-specific aspects of the forecast. In this study, the adjoint-derived observation-impact technique was applied to a function defining the forecast intensity of a TC for two Atlantic hurricane cases: Hurricane Joaquin (2015) and Hurricane Matthew (2016).

A compositing technique was used to draw generalized conclusions about observation impact from otherwise very noisy information on the impact of observations on 


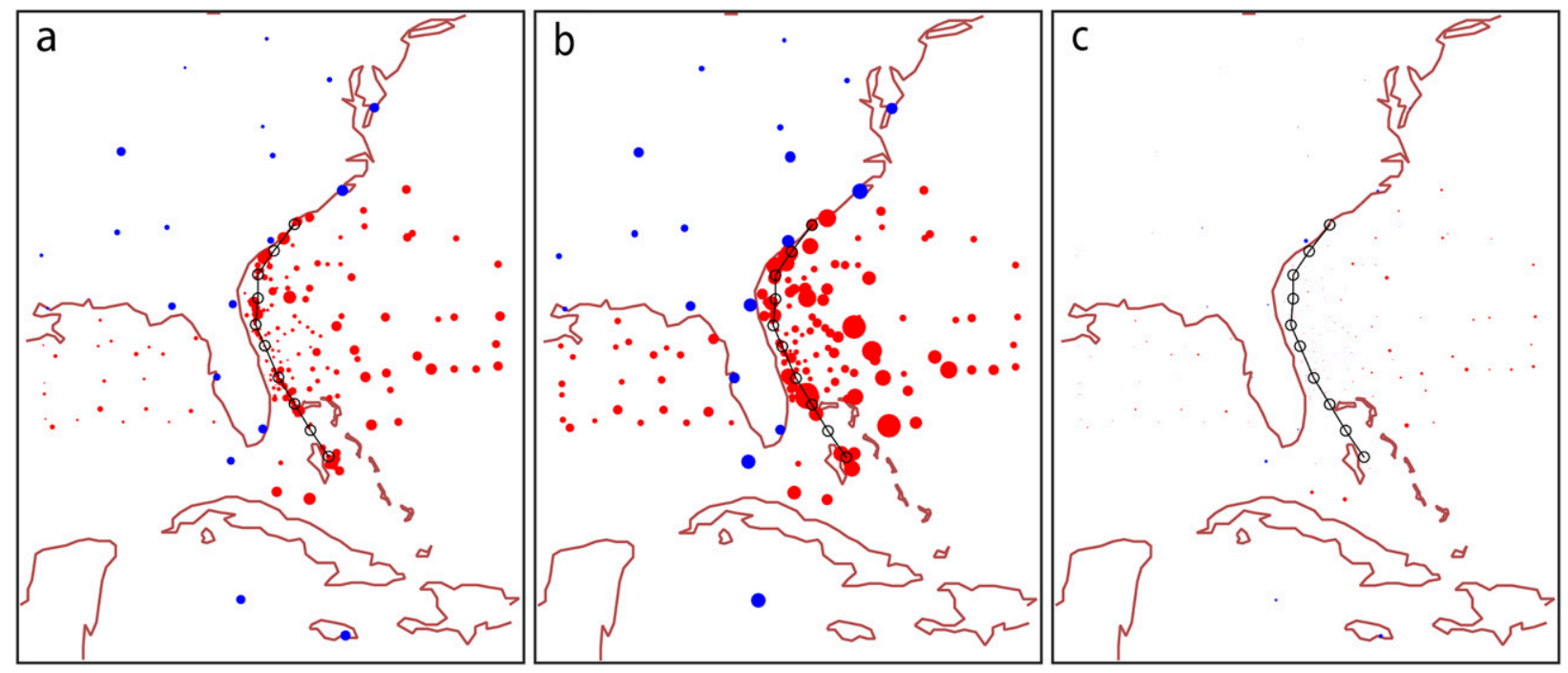

FIG. 12. Composite scatterplot of observation impact of dropwindsonde (red) and nearby rawinsonde (blue) observations between 1200 UTC 6 and 1800 UTC 8 Oct 2016, with dots scaled by absolute value of observation impact on the 24-h intensity forecast of Hurricane Matthew (2016). Observation impact is plotted for (a) temperature observations, (b) wind observations, and (c) moisture observations in relative humidity space. The black line represents the National Hurricane Center best track of Matthew, with black open circles at 0000, 0600, 1200, and 1800 UTC.

the intensity forecast of Joaquin for four forecast lengths (12-, 24-, 36-, and 48-h forecasts), and the resulting composites were used to identify indications of spatially coherent and time-consistent observation impact and how the impact evolves in the forecast.

Composites reveal a general trend toward larger observation impact for longer forecast times, but some observation types trend in the opposite direction, such as synthetic TC observations. Composites show weak spatial coherence in the impact of upper-level wind observations, but the asymmetric distribution of impacts is possibly due to significant interaction of Joaquin with features of the midlatitude flow. Upper-tropospheric temperature observations show significant spatial coherence, expressed as larger impacts and more negative impacts of temperature observations sampling the upstream midlatitude trough for Joaquin. The composite temperature innovations reveal that the observations were continually correcting a cold bias in the model background and that increased divergent flow in the outflow channel on the eastern side of the trough was coincident with these temperature corrections. Wind and temperature observations in the lower troposphere show no significant biases of this kind, with little spatial coherence of observation impact.

Impact of brightness temperature observations expresses spatial coherence in the form of positive (forecast weakening) impact very close to the TC center and negative (forecast intensifying) impact at larger radii. Observation impact of total-column precipitable water tends to be greatest in moisture gradient regions between the TC and nearby drier areas.

Hurricane Matthew (2016) offered an opportunity to compare the impact of temperature, wind, and moisture observations from both reconnaissance dropwindsondes and rawinsondes within similar distances of the cyclone-this was caused by Matthew's track, which followed very close to the coastline along Florida and the Carolinas for an extended period of time, without undergoing landfall. Comparing these observations shows that dropwindsondes appear to express larger impacts than do rawinsondes, especially for temperature and wind observations, and these differences are statistically significant. It is expected that the impact of simplified moisture physics in the adjoint is muting the impact of moisture observations, and their small impact relative to available wind and temperature observations is not considered authoritative.

This study serves as a proof of concept for the observation-impact method as a valuable tool for revealing characteristics of data assimilation relevant to specific aspects of the forecast, which may be difficult or impossible to achieve with other techniques. Future work includes investigating these relationships using more sophisticated adjoints with more fully represented moist physics, producing more comprehensive composites with a greater number of cases, and exploring some issues in data assimilation and their impact on extreme weather.

Future work could also extend beyond the scope of this study to investigate the impact of observations on 
the $\mathrm{TC}$ intensity forecast error, possibly relative to a verifying analysis. A study of this kind may face additional challenges; for example, the forecast model may consistently underpredict the forecast intensity of a TC, and observations that contribute to weakening the TC may be characterized as detrimental, implying they could be excluded from assimilation into the initial conditions to improve the forecast. But those observations may be revealing characteristics of the environment that should impose a weakening on the TC, such as the presence of shear, and their exclusion may more realistically represent the adding of a compensating error into the initial conditions that improves the TC intensity forecast. Future research could also include compositing of cases by segment of TC life cycle, separating periods of intensification and periods of weakening, to observe any potential change in impact based on the phase of storm evolution.

Acknowledgments. The authors thank Dr. Rolf Langland and Dr. Ben Ruston at the Naval Research Laboratory Marine Meteorology Division for their help with running the NAVGEM, NAVDAS-AR, and observation-impact tools. This research was funded through the Office of Naval Research Grant N000141410116.

Data availability statement: All observational data used in this study were made available by the Fleet Numerical Meteorology and Oceanography Center (FNMOC), accessed through the U.S. Navy Department of Defense (DoD) Supercomputing Resource Center (Navy DSRC) established under the DoD High Performance Computing Modernization Program (HPCMP). The NAVDAS-AR and NAVGEM cycled analysis/forecast system was obtained and run on HPCMP resources. These computing resources are restricted and may contain restricted observations.

\section{REFERENCES}

Aberson, S. D., 2010: 10 years of hurricane synoptic surveillance (1997-2006). Mon. Wea. Rev., 138, 1536-1549, https://doi.org/ 10.1175/2009MWR3090.1.

_ 2011: The impact of dropwindsonde data from the THORPEX Pacific area regional campaign and the NOAA hurricane field program on tropical cyclone forecasts in the Global Forecast System. Mon. Wea. Rev., 139, 2689-2703, https://doi.org/10.1175/ 2011MWR3634.1.

, and J. L. Franklin, 1999: Impact on hurricane track and intensity forecasts of GPS dropwindsonde observations from the first-season flights of the NOAA Gulfstream-IV jet aircraft. Bull. Amer. Meteor. Soc., 80, 421-428, https://doi.org/10.1175/ 1520-0477(1999)080<0421:IOHTAI > 2.0.CO;2.

Ancell, B. C., and C. F. Mass, 2006: Structure, growth rates, and tangent linear accuracy of adjoint sensitivities with respect to horizontal and vertical resolution. Mon. Wea. Rev., 134, 29712988, https://doi.org/10.1175/MWR3227.1.
Andersson, E., A. Hollingsworth, G. Kelly, P. Lönnberg, J. Pailleux, and Z. Zhang, 1991: Global observing system experiments on operational statistical retrievals of satellite sounding data. Mon. Wea. Rev., 119, 1851-1865, https://doi.org/10.1175/15200493(1991)119<1851:GOSEOO>2.0.CO;2.

Bauer, P., G. Radnóti, S. Healy, and C. Cardinali, 2014: GNSS radio occultation constellation observing system experiments. Mon. Wea. Rev., 142, 555-572, https://doi.org/10.1175/MWRD-13-00130.1.

- A. Thorpe, and G. Brunet, 2015: The quiet revolution of numerical weather prediction. Nature, 525, 47-55, https:// doi.org/10.1038/nature14956.

Bouttier, F., and G. Kelly, 2001: Observing-system experiments in the ECMWF 4D-Var data assimilation system. Quart. J. Roy. Meteor. Soc., 127, 1469-1488, https://doi.org/10.1002/ qj.49712757419.

Brown, B. R., and G. J. Hakim, 2015: Sensitivity of intensifying Atlantic hurricanes to vortex structure. Quart. J. Roy. Meteor. Soc., 141, 2538-2551, https://doi.org/10.1002/qj.2540.

Burpee, R. W., J. L. Franklin, S. J. Lord, R. E. Tuleya, and S. D. Aberson, 1996: The impact of Omega dropwindsondes on operational hurricane track forecast models. Bull. Amer. Meteor. Soc., 77, 925-934, https://doi.org/10.1175/1520-0477(1996) 077<0925:TIOODO $>2.0 . \mathrm{CO} ; 2$.

Cardinali, C., 2009: Monitoring the observation impact on the short-range forecast. Quart. J. Roy. Meteor. Soc., 135, 239-250, https://doi.org/10.1002/qj.366.

— surements in the ECMWF system using adjoint-based diagnostics. Quart. J. Roy. Meteor. Soc., 140, 2315-2320, https:// doi.org/10.1002/qj.2300.

Charron, M., and Coauthors, 2012: The stratospheric extension of the Canadian global deterministic medium-range weather forecasting system and its impact on tropospheric forecasts. Mon. Wea. Rev., 140, 1924-1944, https://doi.org/10.1175/ MWR-D-11-00097.1.

Chen, J. H., M. S. Peng, C. A. Reynolds, and C. C. Wu, 2009: Interpretation of tropical cyclone forecast sensitivity from the singular vector perspective. J. Atmos. Sci., 66, 3383-3400, https://doi.org/10.1175/2009JAS3063.1.

Chou, K.-H., C.-C. Wu, P.-H. Lin, S. D. Aberson, M. Weissmann, F. Harnisch, and T. Nakazawa, 2011: The impact of dropwindsonde observations on typhoon track forecasts in DOTSTAR and T-PARC. Mon. Wea. Rev., 139, 1728-1743, https://doi.org/ 10.1175/2010MWR3582.1.

Chu, K., and Z. Yi, 2016: Adjoint sensitivity study on idealized explosive cyclogenesis. J. Meteor. Res., 30, 547-558, https:// doi.org/10.1007/s13351-016-5261-5.

Cummings, J. A., and O. M. Smedstad, 2014: Ocean data impact in global HYCOM. J. Atmos. Oceanic Technol., 31, 1771-1791, https://doi.org/10.1175/JTECH-D-14-00011.1.

Dee, D. P., 2005: Bias and data assimilation. Quart. J. Roy. Meteor. Soc., 131, 3323-3343, https://doi.org/10.1256/qj.05.137.

Doyle, J. D., C. A. Reynolds, C. Amerault, and J. Moskaitis, 2012: Adjoint sensitivity and predictability of tropical cyclogenesis. J. Atmos. Sci., 69, 3535-3557, https://doi.org/10.1175/JAS-D12-0110.1.

— C. Amerault, C. A. Reynolds, and P. A. Reinecke, 2014: Initial condition sensitivity and predictability of a severe extratropical cyclone using a moist adjoint. Mon. Wea. Rev., 142, 320-342, https://doi.org/10.1175/MWR-D-13-00201.1.

Errico, R. M., and K. D. Raeder, 1999: An examination of the accuracy of the linearization of a mesoscale model with moist 
physics. Quart. J. Roy. Meteor. Soc., 125, 169-195, https://doi.org/ 10.1002/qj.49712555310.

—_, T. Vukicevic, and K. Raeder, 1993: Examination of the accuracy of a tangent linear model. Tellus, 45A, 462-477, https:// doi.org/10.3402/tellusa.v45i5.15046.

Gelaro, R., and Y. Zhu, 2009: Examination of observation impacts derived from observing system experiments (OSEs) and adjoint models. Tellus, 61A, 179-193, https://doi.org/10.1111/ j.1600-0870.2008.00388.x.

— , R. H. Langland, S. Pellerin, and R. Todling, 2010: The THORPEX Observation Impact Intercomparison Experiment. Mon. Wea. Rev., 138, 4009-4025, https://doi.org/10.1175/ 2010MWR3393.1.

Goerss, J. S., 2009: Impact of satellite observations on the tropical cyclone track forecasts of the Navy Operational Global Atmospheric Prediction System. Mon. Wea. Rev., 137, 41-50, https://doi.org/10.1175/2008MWR2601.1.

_, and R. A. Jeffries, 1994: Assimilation of synthetic tropical cyclone observations into the Navy Operational Global Atmospheric Prediction System. Wea. Forecasting, 9, 557-576, https://doi.org/10.1175/1520-0434(1994)009<0557:AOSTCO > 2.0.CO;2.

Hilton, F., N. C. Atkinson, S. J. English, and J. R. Eyre, 2009: Assimilation of IASI at the Met Office and assessment of its impact through observing system experiments. Quart. J. Roy. Meteor. Soc., 135, 495-505, https://doi.org/10.1002/ qj.379.

Hogan, T. F., and T. E. Rosmond, 1991: The description of the Navy Operational Global Atmospheric Prediction System's spectral forecast model. Mon. Wea. Rev., 119, 1786-1815, https://doi.org/10.1175/1520-0493(1991)119<1786:TDOTNO> 2.0.CO;2.

Holdaway, D., R. Errico, R. Gelaro, and J. G. Kim, 2014: Inclusion of linearized moist physics in NASA's Goddard Earth Observing System data assimilation tools. Mon. Wea. Rev., 142, 414-433, https://doi.org/10.1175/MWR-D-13-00193.1.

Hoover, B. T., 2015: Identifying a barotropic growth mechanism in east Pacific tropical cyclogenesis using adjoint-derived sensitivity gradients. J. Atmos. Sci., 72, 1215-1234, https://doi.org/ 10.1175/JAS-D-14-0053.1.

_ , and R. H. Langland, 2017: Forecast and observation-impact experiments in the Navy Global Environmental Model with assimilation of ECMWF analysis data in the global domain. J. Meteor. Soc. Japan, 95, 369-389, https://doi.org/10.2151/ jmsj.2017-023.

Ishibashi, T., 2010: Optimization of error covariance matrices and estimation of observation data impact in the JMA global 4D-Var system. Research activities in atmospheric and oceanic modelling, CAS/JSC Working Group on Numerical Experimentation Rep. 40, 1.11-1.12.

Joo, S., J. Eyre, and R. Marriott, 2013: The impact of MetOp and other satellite data within the Met Office global NWP system using an adjoint-based sensitivity method. Mon. Wea. Rev., 141, 3331-3342, https://doi.org/10.1175/MWR-D-1200232.1.

Jung, B.-J., H. M. Kim, T. Auligne, X. Zhang, X. Zhang, and X.-Y. Huang, 2013: Adjoint-derived observation impact using WRF in the western North Pacific. Mon. Wea. Rev., 141, 4080-4097, https://doi.org/10.1175/MWR-D-12-00197.1.

Kalnay, E., Y. Ota, T. Miyoshi, and J. Liu, 2012: A simpler formulation of forecast sensitivity to observations: Application to ensemble Kalman filters. Tellus, 64A, 18462, https://oi.org/ 10.3402/TELLUSA.V64I0.18462.
Kim, H. M., and B. J. Jung, 2009: Singular vector structure and evolution of a recurving tropical cyclone. Mon. Wea. Rev., 137, 505-524, https://doi.org/10.1175/2008MWR2643.1.

— S.-M. Kim, and B.-J. Jung, 2011: Real-time adaptive observation guidance using singular vectors for Typhoon Jangmi (200815) in T-PARC 2008. Wea. Forecasting, 26, 634-649, https://doi.org/10.1175/WAF-D-10-05013.1.

Kim, J., H. M. Kim, and C.-H. Cho, 2014: Influence of $\mathrm{CO}_{2}$ observations on the optimized $\mathrm{CO}_{2}$ flux in an ensemble Kalman filter. Atmos. Chem. Phys., 14, 13 515-13 530, https://doi.org/ 10.5194/acp-14-13515-2014.

Kim, M., H. M. Kim, J. W. Kim, S.-M. Kim, C. S. Velden, and B. T. Hoover, 2017: Effect of enhanced satellite-derived atmospheric motion vectors on numerical weather prediction in East Asia using an adjoint-based observation impact method. Wea. Forecasting, 32, 579-594, https://doi.org/10.1175/WAFD-16-0061.1.

Kim, S.-M., and H. M. Kim, 2014: Sampling error of observation impact statistics. Tellus, 66A, 25435, https://doi.org/10.3402/ tellusa.v66.25435.

_ and - 2018: Effect of observation error variance adjustment on numerical weather prediction using forecast sensitivity to error covariance parameters. Tellus, $\mathbf{7 0 A}, 1-16$, https://doi.org/10.1080/16000870.2018.1492839.

Kunii, M., T. Miyoshi, and E. Kalnay, 2012: Estimating the impact of real observations in regional numerical weather prediction using an ensemble Kalman filter. Mon. Wea. Rev., 140, 19751987, https://doi.org/10.1175/MWR-D-11-00205.1.

Langland, R. H., 2005: Observation impact during the North Atlantic TReC-2003. Mon. Wea. Rev., 133, 2297-2309, https:// doi.org/10.1175/MWR2978.1.

— , and R. M. Errico, 1996: Comments on "Use of an adjoint model for finding triggers for Alpine lee cyclogenesis." Mon. Wea. Rev., 124, 757-760, https://doi.org/10.1175/15200493(1996) $124<0757$ :COOAAM > 2.0.CO;2.

— , and N. L. Baker, 2004: Estimation of observation impact using the NRL atmospheric variational data assimilation adjoint system. Tellus, 56A, 189-201, https://doi.org/10.3402/ tellusa.v56i3.14413.

- , R. N. Maue, and C. H. Bishop, 2008: Uncertainty in atmospheric temperature analyses. Tellus, 60A, 598-603, https:// doi.org/10.1111/j.1600-0870.2008.00336.x.

— C. C. Velden, P. M. Pauley, and H. Berger, 2009: Impact of satellite-derived rapid-scan wind observations on numerical model forecasts of Hurricane Katrina. Mon. Wea. Rev., 137, 1615-1622, https://doi.org/10.1175/2008MWR2627.1.

Leslie, L. M., J. F. LeMarshall, R. P. Morison, C. Spinoso, R. J. Purser, N. Pescod, and R. Seecamp, 1998: Improved hurricane track forecasting from the continuous assimilation of high quality satellite wind data. Mon. Wea. Rev., 126, 1248-1258, https://doi.org/10.1175/1520-0493(1998)126<1248:IHTFFT> 2.0.CO;2.

Liu, J., and E. Kalnay, 2008: Estimating observation impact without adjoint model in an ensemble Kalman filter. Quart. J. Roy. Meteor. Soc., 134, 1327-1335, https://doi.org/10.1002/qj.280.

Lorenc, A. C., and R. T. Marriott, 2014: Forecast sensitivity to observations in the Met Office global numerical weather prediction system. Quart. J. Roy. Meteor. Soc., 140, 209-224, https://doi.org/10.1002/qj.2122.

Lupu, C., P. Gauthier, and S. Laroche, 2012: Assessment of the impact of observations on analyses derived from observing system experiments. Mon. Wea. Rev., 140, 245-257, https:// doi.org/10.1175/MWR-D-10-05010.1. 
Mahfouf, J.-F., 1999: Influence of physical processes on the tangent-linear approximation. Tellus, 51A, 147-166, https:// doi.org/10.3402/tellusa.v51i2.12312.

Majumdar, S. J., M. J. Brennan, and K. Howard, 2013: The impact of dropwindsonde and supplemental rawinsonde observations on track forecasts for Hurricane Irene (2011). Wea. Forecasting, 28, 1385-1403, https://doi.org/10.1175/WAF-D-13-00018.1.

Osuri, K. K., U. C. Mohanty, A. Routray, and M. Mohapatra, 2012: The impact of satellite-derived wind data assimilation on track, intensity and structure of tropical cyclones over the north Indian Ocean. Int. J. Remote Sens., 33, 1627-1652, https://doi.org/10.1080/01431161.2011.596849.

Ota, Y., J. C. Derber, E. Kalnay, and T. Miyoshi, 2013: Ensemblebased observation impact estimates using the NCEP GFS. Tellus, 65A, 20038, https://doi.org/10.3402/TELLUSA.v65I0.20038.

Palmer, T. N., R. Gelaro, J. Barkmeijer, and R. Buizza, 1998: Singular vectors, metrics and adaptive observations. J. Atmos. Sci., 55, 633-653, https://doi.org/10.1175/1520-0469(1998) 055<0633:SVMAAO $>2.0 . \mathrm{CO} ; 2$.

Peng, M. S., and C. A. Reynolds, 2006: Sensitivity of tropical cyclone forecasts as revealed by singular vectors. J. Atmos. Sci., 63, 2508-2528, https://doi.org/10.1175/JAS3777.1.

Petersen, R. A., 2016: On the impact and benefits of AMDAR observations in operational forecasting-Part I: A review of the impact of automated aircraft wind and temperature reports. Bull. Amer. Meteor. Soc., 97, 585-602, https://doi.org/ 10.1175/BAMS-D-14-00055.1.

— L L. Cronce, R. Mamrosh, R. Baker, and P. Pauley, 2016: On the impact and future benefits of AMDAR observations in operational forecasting: Part II: Water vapor observations. Bull. Amer. Meteor. Soc., 97, 2117-2133, https://doi.org/10.1175/ BAMS-D-14-00211.1.

Reale, O., E. L. McGrath-Spangler, W. McCarty, D. Holdaway, and R. Gelaro, 2018: Impact of adaptively thinned AIRS cloud-cleared radiances on tropical cyclone representation in a global data assimilation and forecast system. Wea. Forecasting, 33, 909-931, https://doi.org/10.1175/WAF-D-17-0175.1.

Reynolds, C. A., M. S. Peng, and J. H. Chen, 2009: Recurving tropical cyclones: Singular vector sensitivity and downstream impacts. Mon. Wea. Rev., 137, 1320-1337, https://doi.org/ 10.1175/2008MWR2652.1.

— R. Langland, P. M. Pauley, and C. S. Velden, 2013: Tropical cyclone data impact studies: Influence of model bias and synthetic observations. Mon. Wea. Rev., 141, 4373-4394, https:// doi.org/10.1175/MWR-D-12-00300.1.

Rosmond, T. E., 1997: A technical description of the NRL adjoint modeling system. Naval Research Laboratory Rep. NRL/MR/ 7532/97/7230, 62 pp., https://doi.org/10.21236/ADA330960.

- , and L. Xu, 2006: Development of NAVDAS-AR: Non-linear formulation and outer loop tests. Tellus, 58A, 45-58, https:// doi.org/10.1111/j.1600-0870.2006.00148.x.

Tyndall, D. P., and J. D. Horel, 2013: Impacts of mesonet observations on meteorological surface analyses. Wea. Forecasting, 28, 254-269, https://doi.org/10.1175/WAF-D-12-00027.1.

Vukićević, T., and K. Raeder, 1995: Use of an adjoint model for finding triggers for Alpine lee cyclogenesis. Mon. Wea. Rev., 123, 800-816, https://doi.org/10.1175/1520-0493(1995) $123<0800$ :UOAAMF $>2.0 . \mathrm{CO} ; 2$.

Wu, C.-C., K.-H. Chou, P.-H. Lin, S. D. Aberson, M. S. Peng, and T. Nakazawa, 2007: The impact of dropwinsonde data on typhoon track forecasts in DOTSTAR. Wea. Forecasting, 22, 1157-1176, https://doi.org/10.1175/2007WAF2006062.1.

$\mathrm{Xu}, \mathrm{L} ., \mathrm{T}$. Rosmond, and R. Daley, 2005: Development of NAVDAS-AR: Formulation and initial tests of the linear problem. Tellus, 57A, 546-559, https://doi.org/10.3402/ tellusa.v57i4.14710.

Zapotocny, T. H., J. A. Jung, J. F. Le Marshall, and R. E. Treadon, 2007: A two-season impact study of satellite and in situ data in the NCEP Global Data Assimilation System. Wea. Forecasting, 22, 887-909, https://doi.org/10.1175/WAF1025.1.

,,--- , and -2008 : A two-season impact study of four satellite data types and rawinsonde data in the NCEP Global Data Assimilation System. Wea. Forecasting, 23, 80-100, https:// doi.org/10.1175/2007WAF2007010.1.

Zhang, X., H. Wang, X.-Y. Huang, F. Gao, and N. A. Jacobs, 2015: Using adjoint-based forecast sensitivity method to evaluate TAMDAR data impacts on regional forecasts. Adv. Meteor., 2015, 427616, https://doi.org/10.1155/2015/427616. 